\title{
HUMAN CAPITAL REALLOCATION ACROSS FIRMS: EVIDENCE FROM IDIOSYNCRATIC SHOCKS
}

\author{
Erik P. Gilje \\ Jérôme P. Taillard \\ Linghang Zeng \\ Working Paper 29782 \\ http://www.nber.org/papers/w29782 \\ NATIONAL BUREAU OF ECONOMIC RESEARCH \\ 1050 Massachusetts Avenue \\ Cambridge, MA 02138 \\ February 2022
}

We thank seminar participants at Babson College, UMass Lowell, and Dayton Summer Finance Workshop for helpful comments and Aakash Shah for excellent research assistance. The views expressed herein are those of the authors and do not necessarily reflect the views of the National Bureau of Economic Research.

NBER working papers are circulated for discussion and comment purposes. They have not been peer-reviewed or been subject to the review by the NBER Board of Directors that accompanies official NBER publications.

(C) 2022 by Erik P. Gilje, Jérôme P. Taillard, and Linghang Zeng. All rights reserved. Short sections of text, not to exceed two paragraphs, may be quoted without explicit permission provided that full credit, including (C) notice, is given to the source. 
Human Capital Reallocation Across Firms: Evidence from Idiosyncratic Shocks

Erik P. Gilje, Jérôme P. Taillard, and Linghang Zeng

NBER Working Paper No. 29782

February 2022

JEL No. G31,G32,G33,J24

\begin{abstract}
$\underline{\text { ABSTRACT }}$
We study human capital reallocation following firm-specific idiosyncratic shocks. Theory offers diverging predictions as to whether human capital gets reallocated to its most productive use following these shocks. To empirically test these predictions, we focus on relegation battles in the English Premier League. This setting offers well identified idiosyncratic shocks as well as both individual-level and firm-level productivity metrics. We find that human capital exits firms after a negative idiosyncratic shock. Specifically, we find that more productive players move to more productive clubs and maintain their long-term productivity. They get replaced with lower productivity players. Overall, our results show that in a setting with highly transferable skills, idiosyncratic shocks lead to a reallocation of human capital that moves an industry towards a better overall match between individual-level and firm-level productivity.
\end{abstract}

Erik P. Gilje

The Wharton School

University of Pennsylvania

3620 Locust Walk

Philadelphia, PA 19104

and NBER

gilje@wharton.upenn.edu

Jérôme P. Taillard

Babson College

323 Tomasso Hall

Babson Park, MA 02457

United States

jtaillard1@babson.edu
Linghang Zeng

Babson College

231 Forest $\mathrm{St}$

Babson Park, MA 02457

lzeng@babson.edu 


\section{Introduction}

How is human capital reallocated across firms in the economy? Extant research has documented both a rise in the importance of human capital as well as its crucial role in explaining firm decisions (e.g., Zingales (2000), Corrado and Hulten (2010), Peters and Taylor (2017)). However, the existing literature has largely focused on the efficiency of the reallocation of physical capital across firms (e.g., Maksimovic and Phillips (2001), Pulvino (1998)). Evidence on the efficiency of human capital reallocation, which is subject to different dynamics than physical capital as it is intrinsically tied to employees and human interactions, is limited. The objective of this paper is to study the dynamics of human capital following firm specific idiosyncratic shocks to shed light on the efficiency and economic mechanisms driving human capital reallocation. Several lines of inquiry naturally emerge when observing human capital reallocation following a firm specific shock. Namely, which human capital exits and do they go to their most productive use? Which human capital is brought in to fill the void? And ultimately, what is the long-term impact of the shock on the human capital that moves from one firm to another?

Theory offers competing hypotheses as to how human capital reallocation may occur in the economy. To the extent that human capital reallocation behaves like physical capital, a strand of the literature would suggest that when firms perform poorly or are hit by negative shocks, human capital would be reallocated to more productive use in other firms (e.g., Maksimovic and Phillips (2001), Yang (2008)). Alternatively, because human capital relates to employee-employer relationships, existing theories of the firm would argue that firm owners insulate employees from shocks, especially if such shocks are idiosyncratic (e.g., Baily (1974), Azariadis (1975), Guiso et al. (2005)). Such a framework would suggest that firms suffering negative shocks, may work to retain their human capital and stabilize wages, thereby limiting human capital reallocation to a more productive use.

To cleanly empirically test these two competing frameworks of human capital and the firm, one ideally needs to assess how human capital is reallocated following firm specific idiosyncratic shocks. While substantial literature has been devoted to employee dynamics in 
firms under distress, existing empirical evidence is challenged by the fact that firms in these studies are typically exposed to both industry and/or economy wide shocks as well as firm level shocks (e.g., Yagan (2019), Caggese et al. (2019), Baghai et al. (2020), Babina (2020), or Bernstein et al. (2020)). Theoretically, it is well established that asset reallocation can be significantly affected in circumstances where firms with the highest utility for a given asset are also in distress (see Shleifer and Vishny (1992)). Hence, the impact of a negative shock on firms might be very different in the context of a more generalized downturn. Second, to quantify the efficiency of the observed reallocation of human capital, we need observable metrics of productivity at the individual level, which is typically unavailable. Instead, the literature typically uses proxies for individual level productivity such as age, education, and tenure (e.g., Abowd et al. (2009)). Lastly, in order to understand both the short-term and long-term impact of these shocks on human capital, we need to trace the entire career paths of affected individuals following the shock. The granular data necessary for such analysis over time and across firms is also typically unavailable.

To make progress on these empirical challenges, we make use of the professional soccer league in England (English Premier League (EPL)). This approach follows a well-established literature that takes advantage of sports-related settings to obtain detailed data on each individual in the sample (e.g., Kahn (2000), Fee et al. (2006), Brown (2011), and Kleven et al. (2013)). Specifically, we have a complete dataset of all players in the league as well as detailed information on both clubs and players. This player-level data allows us to construct measures of employee level productivity, distinct from firm level productivity measures. Second, given detailed data on transfers including both departing and incoming talent, we can more fully describe human capital redeployment across firms. Lastly, our data allows us to trace over time the entire career path of players. ${ }^{1}$

Our setting has one key additional advantage. Namely, it provides a rare opportunity to sort quasi-randomly treatment and control firms. To obtain exogenous idiosyncratic shocks, we exploit the EPL cutoff rule linked to the determination of which clubs get relegated to

\footnotetext{
${ }^{1}$ It is important to note that we also make use of data from leagues outside the EPL to have a complete career description.
} 
the lower league every season. Our empirical setting offers a clean identification of severe idiosyncratic shocks that, by construction, do not affect the majority of other teams. Specifically, a sharp cutoff is applied to the rank ordering of teams in the EPL at the end of every season, in which the bottom three teams get relegated to the lower division, and the teams above the cutoff remain in the EPL for the following season. ${ }^{2}$ Importantly, we only retain years in which teams are assigned to the treatment group (just above cutoff) or control group (just below cutoff) on the last day of the season. That is, we build our sample of treated and control firms only from the years whereby the ranking of teams before the last game of the season is such that firms above the cutoff could end up below the cutoff after the last game, and conversely those below the cutoff could end up above the cutoff after the last game. In effect, these knife-edge cases represent years where the sorting of treatment and control occurs only on the very last day of the season, which provide the quasi-random nature of the assignment. ${ }^{3}$ Under these conditions, the control group is (1) not affected by the relegation shock and is (2) quasi-identical in its performance relative to the treatment (relegated) group and thus serves as a valid counterfactual.

Our identification relies on the idea that the relegation cutoff is arbitrary, with the bottom three teams being relegated, as opposed to the bottom four, five, or six. One concern may be that teams around the arbitrary cutoff may differ on observable or unobservable characteristics, and that these differences may be a first order driver of the results we find. ${ }^{4}$ While we provide evidence that suggests that many ex ante observables are similar across treatment and control firms, we can also assess more directly the role for potential confounding effects. Specifically, we can adjust the arbitrary cutoff to different thresholds and test whether an arbitrary cutoff higher up in the league table, and hence not associated with relegation, affects the outcomes we focus on. Using "placebo cutoffs" we rerun our main tests and find

\footnotetext{
${ }^{2}$ Both treatment and control firms compete in the same league and have similar objectives. In particular, as opposed to the professional leagues in North America where there is an incentive to end the season with the lowest rank in order to be eligible for the the top picks in the draft, the bottom three EPL teams get relegated to the lower league in the following season.

${ }^{3}$ The empirical design is described in detail in Section 1.

${ }^{4}$ We show that treatment and control groups are not statistically different from each other on many dimensions in Section 2.3. This exercise provides additional empirical support for the validity of our quasinatural experiment design.
} 
no impact on outcomes. If observable or unobservable differences tied to team ranks in close proximity to one another in the league table were driving our effects, one would expect to observe meaningful differences in outcomes. Thus, this placebo-based evidence provides support for the internal validity of our main tests and is consistent with confounding effects associated with slight differences in ex ante rank having limited scope to alter the primary interpretation of our results.

Our first finding confirms that our empirical design leads to a significant and sudden shock to treated firms' revenues and wages paid relative to the control group. In particular, relegation corresponds to a significant productivity shock as measured by lower sales per employee (see Tate and Yang (2015)). The channels through which these relegated teams become far less productive in the lower leagues relate to significantly lower revenues from merchandising, attendance, and most importantly lack of major TV rights contracts. We also show that their total wage expenditures go down significantly following relegation. Of note, total wages correspond to $70 \%$ of total revenues on average. This fact speaks to the critical importance of human capital and talent in this industry.

A key assumption of our empirical framework is that, in the absence of treatment, both treated and control firms' human capital would be similar; this assumption is often referred to as the "parallel trends" assumption. As described above, our treatment and control firms and human capital are by construction very similar in many respects. Empirically, we offer compelling evidence that both treatment and control clubs and their respective human capital are not statistically observationally different from each other at the onset of the shock.

To assess whether relegation leads to a reallocation of talent to more productive clubs (i.e. non-relegated EPL clubs), we track each relegated player in the treatment group and compare them to non-relegated players in the control group in the post-relegation period. We find that following relegation treatment firms' human capital departs on average earlier than at their non-relegated counterparts. This result is driven by the fact that players are significantly more likely to depart the relegated clubs immediately following relegation relative to the control group. In terms of which players leave the treatment firms post-relegation first, we 
find clear evidence that the most productive players depart first. ${ }^{5}$ Further, we find that highly productive human capital is likely to go to the most productive clubs in the industry, i.e. the teams in the EPL. Lastly, we find that these productive employees are replaced by less productive human capital (based on the same proxies for player level productivity).

To assess whether and how a firm-level idiosyncratic shock (i.e., relegation) can impact the long-term productivity of the firm's human capital, we use two proxies to gauge postrelegation career productivity: (1) number of seasons in EPL and (2) cumulative imputed wages during the post relegation career. Among the subset of players who leave during the post-relegation summer transfer window, we find that players from control clubs have a lower post-relegation long-term productivity, while players from treated clubs have better post-relegation long-term productivity. Conversely, for players in the treated club who do not leave within the post-relegation summer transfer window, we find that their long-term productivity measures are lower than for those in the control group. Despite controlling for player level productivity measures over the relegation season, we recognize that the timing of departures is not random. To better control for the unobserved heterogeneity among treatment and control players who leave in the post-relegation summer transfer window, we restrict our analysis to the subset of players from treatment and control players who play in the EPL in the post-relegation season. That is, we compare the players from control clubs that stay in the EPL to the players from treatment clubs that manage to move back into the EPL during the post-relegation summer transfer window. Within that subsample, we find comparable long-term productivity between treatment and control players. Overall, our results suggest that the subset of players of relegated clubs who leave soon after the shock are able to maintain their long-term productivity.

Lastly, as suggested by Roberts and Whited (2012), we perform placebo tests to provide further support for the validity of our empirical design. The placebo tests are the following. Instead of taking the actual relegation cutoff, we select a placebo cutoff in the league ranking three slots above the actual one. We define the placebo treatment and control firms every

\footnotetext{
${ }^{5}$ Player level productivity is measured, for instance, by the number of goals scored, and the number of appearances and minutes played.
} 
season as the three clubs below (respectively above) the placebo cutoff and rerun all of our main tests on this newly defined treatment and control group. Note that in this case, none of the treatment firms actually get relegated at the end of the season. Using this placebo treatment and control group, we find no significant differences in the timing of human capital redeployment, the productivity of transferred players, the likelihood of moving to an EPL club, as well as the long-term productivity of the departed players. Overall, the placebo exercise supports the validity of our empirical setting.

Our study contributes to at least two strands of the literature. The first strand looks at industry wide patterns in asset sales (e.g., see Shleifer and Vishny (1992), Jovanovic and Rousseau (2002), Maksimovic and Phillips (2001), Warusawitharana (2008), and Yang (2008)). The existing literature has focused on firm-level reallocation through M\&A (e.g., Jensen and Ruback (1983)), divisional-level reallocation (e.g., Schlingemann et al. (2002)), and plant-level reallocation (e.g., Maksimovic and Phillips (2001)). We contribute to this literature by analyzing the reallocation of human capital within a given industry. The patterns we observe in the data suggest that human capital reallocation is consistent with the redeployment behavior we observe in physical capital. Yang (2008) develops a dynamic model of asset transactions in the presence of productivity shocks. The model shows that firms with rising productivity buy assets and firms with falling productivity downsize (i.e., "rising buying falling"). Our results are consistent with these predictions but go a step further by also showing that low productivity firms replace their high productivity human capital with lower productivity human capital.

Our study is also directly related to the literature on labor outcomes and distress. This literature finds that talented employees are both the first to leave and the hardest to attract when a firm gets into financial distress (e.g., Brown and Matsa (2016), Caggese et al. (2019), and Baghai et al. (2020)). Our findings are consistent with theirs. Most of these papers look at economy- or industry-wide shocks, therefore the negative effects on labor outcomes and the magnitudes found might be overstated relative to the impact of an idiosyncratic shock to a given firm. One of our contributions is to show what happens to labor outcomes in the context of a shock that is purely firm-specific, with the additional benefit of being able 
to trace the entire career of the human capital being affected by the shock. Other studies, such as Graham et al. (2019), focus on bankruptcies. They find that employees at bankrupt firms suffer significant wage loss relative to the propensity-matched control set, in particular for those who leave the firm around the bankruptcy filing. However, bankruptcies typically capture a gradually decaying business and Baghai et al. (2020) show that talent leaves prior to bankruptcy in Sweden. Relatedly, Gortmaker et al. (2020) show that employees react immediately to their firm's credit deterioration by seeking more connections on LinkedIn. This increase in networking activity is more pronounced among senior workers and occurs well before financial distress. Our study offers novel evidence on labor outcomes when firms suffer from a sharp and sudden shock, that is idiosyncratic in nature. In the context of our study, we find that the ability of the most talented employees to redeploy across the industry can significantly dampen the impact of the shock.

The use of professional soccer leagues in England affords us many empirical advantages. Other studies (e.g., Kleven et al. (2013)) have also taken advantage of professional soccer leagues to address important questions that are typically very challenging to tackle empirically. We do not claim that our results can be generalizable to the entire population. Rather, we view them as more representative of a growing number of industries in the talent economy (e.g., IT, law, finance, sports, entertainment, academia, etc.). In particular, our study highlights some of the conditions (e.g., high transferability of skills and observable individual productivity) under which firm-specific shocks induced in the product market or otherwise can have a limited impact on the affected workforce. ${ }^{6}$

The paper proceeds as follows. In Section 1, we provide the institutional background for our empirical setting. In Section 2 we discuss our data, and in Section 3 we report our empirical results. Section 4 concludes.

\footnotetext{
${ }^{6}$ Our findings complement those of Agrawal and Tambe (2016) who find that PE firms make the labor force of their acquired firms more employable in the long-run by making significant investments in IT, which allows employees to gain more transferable skills.
} 


\section{Empirical Setting}

\subsection{English Premier League and The Relegation Battle}

The English Premier League (EPL) was formed in 1992. It is the most current form of the top professional soccer league in England. ${ }^{7}$ Under the rules of the league, every season, the bottom three teams of the league get relegated, while the other teams remain in the EPL for the coming season. ${ }^{8}$ The bottom three teams are replaced by the best teams of the Championship league (the second-highest professional soccer league in England). ${ }^{9}$

Each season runs from August to May starting with the 1992/1993 season. Up to the 1995/1996 season, each team plays 42 games (21 home and away games in a league of 22 teams). As of the 1995/1996 season, each team plays 38 games (19 home and away games in a league of 20 teams). Each game won earns a team three points, while a draw gives one point, and a defeat grants no points.

Being in the EPL is highly lucrative for any given team. From TV rights to merchandising to stadium attendance-related revenues, being in the top league confers each team significant prestige and associated revenues. Hence each club is highly incentivized to remain in the EPL. The lower ranked teams compete until the very last day of the season to determine who remains in the league and who gets relegated. We exploit this relegation battle to devise a setting that creates a substantial and sudden shock to the firms that get relegated and a natural control group using the firms that managed to maintain EPL status on the very last day of the season.

Specifically, the league rules specify that the three lowest ranked teams based on points earned during the entire season get relegated to the lower league. All teams above the cutoff (4th from bottom and above) remain in the league for the next season. ${ }^{10}$ It is important

\footnotetext{
${ }^{7}$ The top league competition in England was formerly known as the First Division and ran from 1888 to 1992.

${ }^{8}$ The only exception is during the 1994/1995 season when the bottom four teams were relegated (and only two promoted) as the EPL decided to go from 22 to 20 league teams.

${ }^{9}$ The first two teams of the Championship league are automatically promoted and the 3rd to the 6 th placed teams play each other in playoffs to determine who gets the third promotion slot.

${ }^{10}$ Again, the only exception is during the 1994/1995 season when only the 5th team from the bottom and above remained.
} 
to note that, by construction, there cannot be any "bunching" above the cutoff: the three bottom teams in terms of points after the last game of the season get relegated. EPL clubs are aware of the cutoff rule and aim to earn enough points throughout the season to finish above the cutoff.

Our setting offers another advantage empirically. That is, we can observe a clear time frame during which players can move from one club to another. In particular, we have the "summer transfer window" that takes place between May and August every year. During this window, we can observe the reallocation of human capital before the "next period", i.e. prior to the beginning of the next season (see Appendix Figure 1).

\subsection{Exogenous Shock}

The clubs below the relegation cutoff suffer a significant shock to their business through relegation to the lower league the following season. However, the empirical design needs to ensure that clubs and their human capital (players) for the treatment and control groups are otherwise identical. It is obvious for instance that a club that is lingering at the bottom of the league throughout most of the season is going to be significantly different (weaker) than its peer EPL firms. As such, we focus only on the teams closest to the cutoff, i.e. those ending just above or below the cutoff on the last day of the season, and thereby qualifying for a quasi-random treatment effect.

Panel A of Table 1 shows how the selection of treatment and control works with a concrete example using the 2010-2011 season. In the left column, we select in grey the clubs that can still be either relegated (within three points of a club in the bottom three positions) or maintain EPL status (within three points of a club above the bottom three clubs) before the last game. The assignment to treatment and control only occurs after the last game of the season whereby those that could maintain status before the last game but ended up in the bottom three positions are assigned to the treatment group (in red in the right column), while those that could get relegated but managed to maintain their EPL status are assigned to the control group (in green in the right column). This table highlights the quasi-random 
nature of the assignment as the final ranking depends on the results from all the clubs shaded in grey in the left column as well as all their opponents and how they fare against each other on the last day of the league. Although every team will do their best to end up above the relegation cutoff, their fate is typically not in their full control as they depend on results from other teams fighting in the relegation battle.

Panel B shows the full sample of treatment and control firms stemming from this empirical design for every season since the creation of the English Premier League in 1992 (first season ending in 1993). ${ }^{11}$ Our restrictive criteria in terms of assignment to treatment and control eliminates seven seasons where the assignment to the bottom three was already settled prior to the last game of the season. ${ }^{12}$ Conversely, for 19 of the 26 seasons since the creation of the EPL, the final ranking on points (and corresponding assignment) is determined from the outcome of the last game day of the season. In order to have enough post-relegation data, we take out from our final sample the 2017-2018 season, despite meeting our strict selection criteria. It is important to note that several teams can be involved in the relegation battle until the last season game and hence can lead to many instances with more than one control and treatment firm for a given season. ${ }^{13}$ Lastly, we note that in some seasons, there is only one treatment firm that satisfies our strict selection criteria. This means the bottom two teams are already condemned to relegation prior to the last game of the season and point to them being structurally weaker and hence disqualifies them from the empirical design.

A dynamic graphical representation of the evolution of league rankings towards the end of the season is provided in Appendix Figure 2. It provides the evolution of club rankings around the relegation cutoff over the last eight games of the 2010-2011 season in the English Premier League (EPL). Specifically, it graphs the dynamic ranking of the clubs that end

\footnotetext{
${ }^{11}$ In the season ending in 1995, four clubs were relegated in order to adjust the league to 20 teams going forward (from 22 teams before). Among the four relegated clubs that season, only Crystal Palace was still able to maintain EPL status going into the last game of the season.

${ }^{12}$ Interestingly, most of the seasons where the bottom three were determined prior to the last game of the season, i.e. seasons that did not qualify for our empirical design due to greater segmentation of the teams at the bottom of the league have occurred in more recent years.

${ }^{13}$ The fact that 2015 saw the "closest" control to be three ranks above the relegation bar happened because the team that was the closest to relegation in the last but one season game surpassed the two teams "already saved" from relegation by winning in the last game of the season.
} 
the league season in the bottom nine positions in the league table; namely the bottom three below the "relegation bar" (cutoff) as well as the six clubs above the cutoff. The bottom three clubs are relegated to play in the lower league (Championship League) the following season, while all other clubs maintain their EPL status the following season. As a visual aid, we plot with continuous lines the evolution of the clubs that are respectively just below (above) the relegation cutoff at the end of the season.

\section{Data}

\subsection{Construction of Dataset}

English Premier League (EPL) information with detailed rankings for each season, and after each game played was downloaded from www.11v11.co.uk. This data was used to determine our final sample of treatment and control firms following the procedure described in Section 2.

For firm-level financials, we hand collect club-level financial statements for all clubs in the EPL and Championship League from 1992-1993 season to 2018-2019 season from Companies House. ${ }^{14}$ We read through each financial statement and collect data on revenues and total wages.

Figure 1 provides a snapshot of the website Transfermarkt (www.transfermarkt.de), our main data source for player-level information. The website offers detailed transfer data and annual statistics on each professional soccer player. This data allows us to create a complete player-level dataset, which includes many characteristics including personal information (such as age and height), as well as productivity data (such as the number of games played across all competitions) and performance data (such as goals scored across all competitions). The example illustrates the richness of the dataset by providing a snapshot of David Beckham's track record. Panel A provides the complete record of transfers, including transfer fees, as well as free transfer status and loan status when that is the case. It is important to note

\footnotetext{
${ }^{14}$ Internet source: https://www.gov.uk/government/organisations/companies-house.
} 
that at the end of a contract, a player is free to leave the club. As such, his new club does not need to pay the former club a transfer fee and the player moves on a "free transfer" in that case. ${ }^{15}$ Lastly, there are a non-trivial number of loans that occur in the dataset. Clubs have a deep roster of talent. In many cases, to guarantee play time and further develop a player before he can make it to the main team, he is sent on loan to another club. The loaned player is still under contract with the original team and as such, we do not consider loans as transfers. Panel B provides a snapshot of the annual statistics for the player across all competitions (league + cup). From this website, we get a significant number of player characteristics (e.g., field positions) for our treatment and control clubs summarized in Table 2. ${ }^{16}$ For all players in the treatment and control clubs, we download all the transfer records and statistics data up to June 2019 using web scraping techniques. Our final sample includes 1250 players associated with 60 clubs.

\section{$2.2 \quad$ Summary Statistics}

Table 2 combines the club-level and player-level data for both the treatment and control clubs that qualify our stringent selection criteria described in Section 2. Panel A reports summary statistics for club-level characteristics. On average, a club in our final sample has 21 players, has played three of the last five previous seasons in the English Premier League (EPL), earns GBP 48M in the relegation season and has a wage expenditure of GBP $33 \mathrm{M} .{ }^{17}$ It is noteworthy to highlight that wages correspond to $70 \%$ of total revenues and is reflective of the fact that human capital is the most valuable asset for our sample firms, similarly to top executives, investment bankers, corporate lawyers and other professional sports teams in North America (see Kaplan and Rauh (2010)).

At the player level, we offer statistics for the relegation seasons. We have 1250 players across all treatment and control clubs. They play on average 20 games over the season, approximately 1500 minutes on the field, and score slightly less than two goals in the season,

\footnotetext{
${ }^{15}$ The new club's only cost for this player corresponds to his wages.

${ }^{16}$ Goalkeepers are excluded from our study.

${ }^{17}$ All numbers are UK CPI inflation adjusted (2019 base year).
} 
with .5 assists made. The distribution of assists and goals is highly skewed, with forwards making the largest portion of the biggest goal scorers given their position on the field. We also offer statistics for all seasons prior to the relegation season. We find they have on average 125 appearances prior to the relegation year, with correspondingly a larger amount of minutes played, goals scored, and assists made.

On average, the sample player is 27 years old and has been at the club slightly less than three years (31 months). The prior transfer fee is about USD3.5M when available. ${ }^{18}$ It is important to note that many players come to a club on a "free transfer" when their contract with their previous club expires. In such cases, they are free to move to any club and no fees are exchanged between the clubs. Clubs are also responsible for players' wages. Unfortunately, that data is typically not disclosed at the individual player level.

We offer some broad characteristics of mobility and other post relegation statistics in Table 2. Namely, players stay with their club on average two years (24 months) following a relegation season, with $22 \%$ leaving within three months of the relegation, i.e. during the post-relegation summer transfer window (Summer_Transfer variable). A quarter of them go to a club that plays in the EPL the following season. On average, across relegated (treated) and maintained (control) clubs, a player has on average 2.3 seasons in the EPL after the relegation season. Lastly, we will note that we have $39 \%$ of players as defenders, $32.5 \%$ as midfielders, and $28 \%$ as forwards, reflecting a rather even spread across the different field positions, albeit with fewer forwards and disproportionately more defenders.

\subsection{Validity of Empirical Design}

In Table 3, we provide the results of several tests designed to test the validity of our empirical setting. In Panel A of Table 3, we test whether there are significant club-level differences between treatment and control firms prior to the shock. Specifically, we run a regression of the numbers of years in the English Premier League (EPL) in the past five (left column), three (middle column) and one (right column) year prior to the relegation season. We include

\footnotetext{
${ }^{18}$ Transfermarkt provides transfer fees in USD. All numbers are UK CPI inflation adjusted (2019 based year).
} 
both a treated dummy, as well as cohort (relegation year) fixed effects. We find no significant differences across treatment and control firms.

In Panel B of Table 3, we test whether there are significant player-level differences across treatment and control firms. In each of the columns, we have a player-level characteristic explained by a treatment dummy as well as cohort (relegation year) fixed effects. The first four columns (1)-(4) reports on player-level statistics in the relegation season, namely number of game appearances, minutes played, goals scored and assists made. The next four columns (5)-(8) focus on the player-level statistics from their entire career up to the beginning of the relegation season. The last three columns run the same regressions as before on the following player-level characteristics: age, tenure at the club (in months), and transfer fees (if any) when joining the club (in USD). Across all dimensions, we do not find any statistically significant differences at the player level across treatment and control firms.

To further confirm the validity of our empirical design, we show in Figure 2 the evolution of revenues (Panel A) and wages (Panel B) in event time around the relegation year $(\mathrm{t}=0)$ across treatment and control clubs. Specifically, we run a regression in event time around each relegation year whereby the dependent variable is revenues (respectively wages) and the figure plots the yearly coefficients on the treated indicator reflecting the difference in revenues between treatment and control every year relative to the baseline year at time zero. The $95 \%$ confidence interval is also plotted for each of these coefficients. The specification includes both club times relegation year (cohort) fixed effects as well as event year times relegation year (cohort) fixed effects. It is clear from both panels that the "parallel trends" assumption (see Roberts and Whited (2012)) are satisfied. Specifically, we find no statistical difference both in terms of revenues and wage expenditures across treatment and control prior to the relegation year. Further, it is clear from these charts that there is a meaningful drop in both revenues and wage expenditures for treated firms following their relegation. ${ }^{19}$ These figures highlight unequivocally the acute nature of the shock that is induced by getting relegated relative to the clubs that managed to maintain their EPL status on the last game of the

\footnotetext{
${ }^{19}$ The increase witnessed at time $t=2$ in terms of revenues is driven by three outliers, namely Hull City, Newcastle, and Norwich City. All three manage to get promoted back into the EPL after one year in the Championship league.
} 
season. Lastly, given (1) the drop in revenues and (2) the fact that the number of players is approximately constant after relegation, we can conclude that getting relegated corresponds to a significant productivity shock as measured by lower sales per employee (see Tate and Yang (2015)).

\section{Results}

In this section, we first analyze the timing of human capital redeployment following the firm-specific productivity shock caused by relegation. We then focus our attention on which human capital is transferred, to whom they are transferred, and how they are replaced. Lastly, we look at the long-term productivity of the human capital transferred in order to determine the long-term consequences of the firm-specific shock.

\subsection{Timing of Human Capital Redeployment}

In this section, we gauge the timing of human capital redeployment following relegation. Graphically, we show in Figure 3 the proportion of players who leave their clubs following relegation, across both treated (relegated) and control (non-relegated) clubs. The duration is in months. The first two bars represent the proportion of players leaving within three months of being relegated. This window corresponds to the summer transfer window that occurs between relegation and the start of the next season. The center bars highlight the proportion of players that leave between four months and two years after relegation. And the right bars show the proportion of players that leave two years or more after the relegation. We find a visually striking pattern: the proportion of players leaving in the three month window after the season ends is much greater for treatment (relegated) clubs than control (non-relegated) clubs. And because they have to sum up to one, the proportions are flipped for the longer duration bins, whereby the proportions of departures occurring beyond the first summer transfer window are larger for control groups. It seems from this figure that the human capital redeployment pattern for treated firms is different than that of control firms. 
To provide statistical analysis around the findings described above, we estimate in Table 4 both the duration of stay in a club post-relegation, as well as the likelihood of leaving within three months, i.e. during the first transfer window post-relegation. Specifically, in the first column of Table 4, we model the amount of time (in months) a player stays with the club after the relegation season. In the second and third column, we focus specifically on transfers that occur within the summer transfer window that corresponds to the three months between relegation and the start of the next season ("Summer_Transfer"). This three month window matters for the following reason: if a player does not leave by the end of August he will have to remain at the club - and get paid - at least until the next transfer window if he is to play in the EPL. ${ }^{20}$ In the second column, we estimate the likelihood of a post-relegation summer transfer using a linear probability model. In the third column, we estimate the likelihood of a post-relegation summer transfer using a logistic model and report the odds ratio. For each specification, we include a treatment dummy as well as cohort (relegation year) fixed effects. Standard errors are clustered at the club-relegation year level.

Our results are consistent across all three specifications. Column (1) shows that players among treated clubs stay at the club four months less than players among control clubs. This result could stem from a combination of post-relegation summer transfers from the club, higher propensity to not have contracts renewed, and early retirements. To focus more directly on the likelihood of post-relegation summer transfers, columns (2) and (3) of Table 4 estimate the likelihood of a rapid departure of human capital following relegation. Both specifications find a significant increase in the odds of leaving the club within the first transfer window following relegation for treated clubs relative to control clubs. The linear probability model in column (2) indicates that the likelihood of a post-relegation summer transfer in the treatment club is 10 percentage points higher (corresponding to $43.7 \%$ of the average likelihood) This result supports statistically the graphical evidence of Figure 3, namely that in terms of human capital redeployment, clubs that suffer a relegation shock are significantly

\footnotetext{
${ }^{20}$ The next window is the "winter window" starting on January 1st, which implies at least an additional half season if not transferred over the previous summer transfer window. To be precise, the official summer transfer window was instituted during the $2002 / 2003$ season. Our data suggests that even before that, most transfers occurred over the summer.
} 
more likely to see their players leave during the first transfer window available to them.

\subsection{Productivity of Human Capital Transferred}

In this section, we gauge the productivity of departing (Table 5) and incoming (Table 6) human capital following relegation. Table 5 presents OLS regression estimates related to the productivity of human capital that leaves the treatment and control firms. Productivity is measured using several proxies: (1) the number of appearances in the previous season (column 1), (2) the number of minutes played in the previous season (column 2), (3) the number of goals scored in the previous season (column 3) and (4) the number of assists made in the previous season (column 4). For each specification, the sample consists of all human capital from treated and control firms and we include a treatment dummy (Treated), a dummy that takes the value of 1 for all transfers within the post-relegation summer transfer window (Summer_Transfer), and the interaction term between the two (Treated $\times$ Summer_Transfer), as well as cohort (relegation year) fixed effects.

We find a notable dichotomy when focusing on players who leave their clubs in the first transfer window immediately following relegation. In particular, we find that control clubs that maintain their EPL are more likely to see their low productivity workers leave early (negative and significant coefficient on Summer_Transfer). Conversely, the treatment (relegated) clubs are more likely to witness an early departure of their high productivity workers (positive and significant coefficient on Treated x Summer_Transfer). Specifically, the coefficient estimate of the interaction term in column 1 is 4.7 (corresponding to $23.5 \%$ of the average appearances) and 0.8 in column 3 (corresponding to $46.3 \%$ of the average number of goals). This result points to a very different outcome in terms of human capital redeployment depending on whether the club managed to avoid relegation or not. In particular, treated firms are significantly more likely to see their more productive human capital leave in the first transfer window following relegation relative to control clubs. Figure 4 presents graphically these results. Specifically, Panel A highlights the relatively greater number of players with low productivity leaving the control group in the summer transfer window following 
relegation (red line above blue line at low levels of productivity as measured by number of minutes played during the relegation season), as well as the relatively greater number of players with high productivity leaving the treatment group in the summer transfer window following relegation (blue line over red line at high levels of productivity as measured by number of minutes played during the relegation year). Panel B shows very similar patterns across both treatment and control for transfers that occur between 4 and 24 months following the relegation season. And as Panel $\mathrm{C}$ includes every remaining player that has not departed before two years following the relegation season, we find results that are the reverse image of Panel A.

In Table 6, we build on our findings in Table 5 and focus only on the post-relegation summer transfer window. In particular, we now want to contrast the departures from the arrivals during that summer window. The arrival of new players can be viewed as replacement human capital for clubs. Table 6 shows estimates related to the productivity of replacement human capital by the treatment and control firms over that post-relegation summer transfer window. Productivity is measured as before: (1) the number of appearances in the previous season (column 1), (2) the number of minutes played in the previous season (column 2), (3) the number of goals scored in the previous season (column 3) and (4) the number of assists made in the previous season (column 4). For each specification, the sample consists of all transfers made by treated and control firms during the post-relegation summer transfer window. We include a treatment dummy (Treated), a replacement dummy (Replacement), and the interaction term of the two (Treated $\mathrm{x}$ Replacement), as well as cohort (relegation year) fixed effects. Standard errors are clustered at the club-relegation year level.

Table 6 shows that the productivity of incoming (replacement) human capital is significantly lower for treated (relegated) clubs. That is, treatment firms transfer their most productive human capital (coefficient on Treated significantly positive) and replace them with lower productivity players (significantly negative sign on interaction term). ${ }^{21}$ The results are

\footnotetext{
${ }^{21}$ Table 5 results highlighted that players transferred by treatment and control clubs in the post-relegation summer window have very high productivity, as measured by statistics based on their EPL performance. This explains why there is a negative sign on the purchase coefficient in these specifications; structurally, there will be acquisitions of players who will not have been playing in the EPL the previous season (e.g., players
} 
strong across all specifications.

\subsection{Human Capital Reallocation}

To complement findings of Table 5 and 6, we analyze next the reallocation of human capital following the relegation season. For that, recall that the English Premier League (EPL) is the highest professional league in England with the highest productivity levels. The model we estimate explains the likelihood of having a transfer of human capital to an EPL club in the seasons that follow relegation. The model includes a treatment (relegated) dummy, a postrelegation summer transfer dummy (Summer_Transfer) and the interaction term (Treated x Summer_Transfer), as well as cohort (relegation year) fixed effects. In Column 1, we use a linear probability model (LPM). In Column 2, we use a logistic model (Logit) and report the odds ratio.

In both specifications, we find a statistically significant positive coefficient on the interaction term. That is, the likelihood of leaving for an EPL club in the post-relegation summer transfer window (as opposed to later on) is relatively greater for individuals at the relegated clubs than those at the control clubs. These findings are presented graphically in Figure 5, whereby there is a significantly greater proportion of players that go to EPL clubs among those who depart from relegated clubs (relative to control clubs) during the post-relegation summer transfer window relative to both the (1) "four months to 24 months" post-relegation window, as well as the (2) "> 24 months" post-relegation window.

Overall, the findings of Tables 5 through 7 as well as Figure 3 through 5 speak directly to the fundamental motivation of our paper. That is, does human capital have redeployment features across firms, similar to what has been documented with physical capital, as in Maksimovic and Phillips (2001)? Or do owners in effect provide insurance to the human capital at the firm, and work to retain its human capital in response to idiosyncratic shocks? This alternative hypothesis would suggest that productive human capital may not be as

coming from abroad, or the Championship league), in which case they have zero productivity according to our EPL-based measures. In essence we are assuming that anyone playing in leagues outside of the EPL the previous season has relatively speaking very low productivity. 
fungible or redeployable as physical capital. The patterns in the data we observe suggests that human capital reallocation is consistent with the redeployment behavior we observe in physical capital. Specifically, we find that lower productivity (relegated) clubs transfer high productivity human capital to high productivity clubs. This result is also consistent with the predictions of Yang (2008), but goes a step further, because we also show that low productivity firms replace their high productivity human capital with lower productivity human capital.

\subsection{Long-Term Productivity}

This section assesses the long-term impact of relegation (exogenous shock) on human capital productivity. It is an empirical question as to whether the human capital of the treated firms suffer any long lasting damage to their productivity and cumulative earnings. To tackle this issue, in Panel A of Table 8, we take all treatment and control players and trace over time the number of seasons in the English Premier League (EPL) they experience post relegation season in column 1, and the total imputed post-relegation wages in column 2. For the imputed wages, we hand-collect club-level wage expenditures for every club in both the EPL and Championship league and create a salary index from it, and then apply these club-level index values to the players, implicitly assuming uniform pay distribution across players in each club. ${ }^{22}$ The models include a treatment (relegated) dummy, a post-relegation summer transfer dummy (Summer_Transfer) and the interaction term (Treated x Summer_Transfer), as well as cohort (relegation year) fixed effects. We also control for player level productivity measures in the relegation season (appearances, minutes, goals, and assists).

We find contrasting results across treatment and control when it comes to early departures. In those cases, players from control clubs have a lower post-relegation season track record, while players from treated clubs have a better post-relegation season track record. Conversely, for players in the treated club who do not leave within the post-relegation summer transfer window, we find that their long-term productivity measures are lower than for

\footnotetext{
${ }^{22}$ We recognize the limitations of this assumption in our imputed measure of earnings. A similar approach is used in Ellul et al. (2020).
} 
those in the control group.

Despite controlling for player level productivity measures over the relegation season in Panel A, we recognize that these early departures are not random. To better control for the unobserved heterogeneity among treatment and control players who leave in the postrelegation summer transfer window, we restrict our analysis to the subset of players from treatment and control players who play in the EPL in the post-relegation season. That is, we focus only on the subset of players who (1) were among the treated clubs but left for an EPL club in the post-relegation summer transfer window or (2) were in a control club and stayed for at least another season in that club or left for another EPL club during the summer transfer window. We compare these players along the same two proxies of long-term productivity. The models include a treatment (relegated) dummy to distinguish the players who were at a treated firm from those that come from a control firm. We find no significant differences in terms of the number of EPL seasons and a marginally significant positive coefficient on the treated dummy for our total imputed wage measure. These results suggest that relegated players who leave for an EPL club during the post-relegation summer transfer window maintain their long-run productivity compared to their non-relegated counterparts.

\subsection{Placebo Tests}

The placebo tests we run are the following. Instead of taking the actual relegation cutoff, we select a placebo cutoff in the league ranking three slots above the actual one. We define the placebo treatment and control firms for every season of the original sample as the three clubs below (respectively above) the placebo cutoff and rerun all of our main tests on this newly defined treatment and control group. Note that in this case, none of the treatment firms actually get relegated at the end of the season. Table 9, Panels A through D rerun our main specifications from Tables 4, 5, 7, and 8 respectively. Reassuringly, we find none of our key results described above. That is, using this placebo treatment and control group, we find no significant differences in the timing of human capital redeployment, the productivity of transferred human capital, the likelihood of leaving to an EPL club, as well as the long- 
term productivity of the players. Overall, the placebo exercise supports the validity of our empirical setting.

\section{Conclusion}

What happens to a firm's human capital when it gets hit by a negative firm-specific shock? It is typically challenging to study this question as most shocks suffered by firms are caused by industry-wide (or economy-wide) downturns. We investigate this question using a unique setting provided by the relegation battles at the end of each season in the top professional soccer league in England, the English Premier League (EPL). This setting offers a very attractive research design as it provides natural comparison groups of treated (relegated) and control (non-relegated) firms. Relegation leads to a severe and sudden shock to a club's productivity. Using detailed player-level data, we find that the most productive human capital is more likely to leave the club shortly after relegation. They are also more likely to move to a more productive club. Relegated clubs replace their departed human capital with less productive players. Further, players from treatment clubs who manage to transfer during the post-relegation summer transfer window do not suffer long-term consequences in terms of productivity and career outcomes. We conjecture that they benefit from being in an industry whereby talent is observable, paramount and highly transferable.

Ultimately, in the context of idiosyncratic shocks, the redeployability of human capital offers a chance for labor to not suffer the same fate as their employer. Our quasi-experimental setting allows us to make progress in our understanding of how firms interact with each other through the labor market channel. In particular, our evidence shows that there are reallocation mechanisms to absorb the impact of firm-specific shocks on human capital. 


\section{References}

Abowd, J. M., J. Haltiwanger, R. Jarmin, J. Lane, P. Lengermann, K. McCue, K. McKinney, and K. Sandusky (2009). The relation among human capital, productivity, and market value: Building up from micro evidence. In Measuring capital in the new economy, pp. 153-204. University of Chicago Press.

Agrawal, A. and P. Tambe (2016). Private equity and workers' career paths: The role of technological change. The Review of Financial Studies 29(9), 2455-2489.

Azariadis, C. (1975). Implicit contracts and underemployment equilibria. Journal of Political Economy 83(6), 1183-1202.

Babina, T. (2020). Destructive creation at work: How financial distress spurs entrepreneurship. Review of Financial Studies 33(9), 4061-4101.

Baghai, R., R. Silva, V. Thell, and V. Vig (2020). Talent in distressed firms: Investigating the labor costs of financial distress. Journal of Finance forthcoming.

Baily, M. N. (1974). Wages and employment under uncertain demand. Review of Economic Studies $41(1), 37-50$.

Bernstein, S., R. Townsend, and T. Xu (2020). Flight to safety: How economic downturns affect talent flows to startups. NBER Working Paper (w27907).

Brown, J. (2011). Quitters never win: The (adverse) incentive effects of competing with superstars. Journal of Political Economy 119(5), 982-1013.

Brown, J. and D. A. Matsa (2016). Boarding a sinking ship? an investigation of job applications to distressed firms. Journal of Finance 71(2), 507-550.

Caggese, A., V. Cunat, and D. Metzger (2019). Firing the wrong workers: Financing constraints and labor misallocation. Journal of Financial Economics 133, 589-607. 
Corrado, C. A. and C. R. Hulten (2010). How do you measure a" technological revolution"? American Economic Review 100(2), 99-104.

Ellul, A., M. Pagano, and A. Scognamiglio (2020). Career risk and market discipline in asset management. Review of Financial Studies 33(2), 783-828.

Fee, C. E., C. J. Hadlock, and J. R. Pierce (2006). Promotions in the internal and external labor market: Evidence from professional football coaching careers. The Journal of Business $79(2), 821-850$.

Gortmaker, J., J. Jeffers, and M. Lee (2020). Labor reactions to credit deterioration: Evidence from linkedin activity. Available at SSRN 3456285.

Graham, J. R., H. Kim, S. Li, and J. Qiu (2019). Employee costs of corporate bankruptcy. Technical report, National Bureau of Economic Research.

Guiso, L., L. Pistaferri, and F. Schivardi (2005). Insurance within the firm. Journal of Political Economy 113(5), 1054-1087.

Jensen, M. C. and R. S. Ruback (1983). The market for corporate control: The scientific evidence. Journal of Financial economics 11(1-4), 5-50.

Jovanovic, B. and P. L. Rousseau (2002). The q-theory of mergers. American Economic Review 92(2), 198-204.

Kahn, L. M. (2000). The sports business as a labor market laboratory. Journal of economic perspectives $14(3), 75-94$.

Kaplan, S. N. and J. Rauh (2010). Wall street and main street: What contributes to the rise in the highest incomes? Review of Financial Studies 23(3), 1004-1050.

Kleven, H. J., C. Landais, and E. Saez (2013). Taxation and international migration of superstars: Evidence from the european football market. American economic review 103(5), $1892-1924$. 
Maksimovic, V. and G. Phillips (2001). The market for corporate assets: Who engages in mergers and asset sales and are there efficiency gains? Journal of Finance 56(6), 20192065.

Peters, R. H. and L. A. Taylor (2017). Intangible capital and the investment-q relation. Journal of Financial Economics 123(2), 251-272.

Pulvino, T. (1998). Do asset fire sales exist? an empirical investigation of commercial aircraft transactions. Journal of Finance 53, 939-978.

Roberts, M. R. and T. M. Whited (2012). Endogeneity in empirical corporate finance. In G. Constantinides, M. Harris, and R. Stulz (Eds.), Handbook of the economics of finance, Volume 2. Elsevier.

Schlingemann, F. P., R. M. Stulz, and R. A. Walkling (2002). Divestitures and the liquidity of the market for corporate assets. Journal of Financial Economics 64 (1), 117-144.

Shleifer, A. and R. Vishny (1992). Liquidation values and debt capacity: A market equilibrium approach. Journal of Finance 4\%, 1343-1366.

Tate, G. and L. Yang (2015). The bright side of corporate diversification: Evidence from internal labor markets. Review of Financial Studies 28(8), 2203-2249.

Warusawitharana, M. (2008). Corporate asset purchases and sales: Theory and evidence. Journal of Financial Economics 87(2), 471-497.

Yagan, D. (2019). Employment hysteresis from the great recession. Journal of Political Economy 127(5), 2505-2558.

Yang, L. (2008). The real determinants of asset sales. Journal of Finance 63(5), 2231-2262.

Zingales, L. (2000). In search of new foundations. Journal of Finance 55(4), 1623-1653. 


\section{Figure 1: Transfermarkt}

This figure provides a snapshot of the website Transfermarkt (www.transfermarkt.de), our main data source for this study. The website offers detailed transfer data and annual statistics on each player. This data allows us to create a complete player-level dataset, which includes many characteristics including personal information (such as age and height), as well as productivity data (such as the number of games played across all competitions) and performance data (such as goals scored across all competitions). The example illustrates the richness of the dataset by providing a snapshot of David Beckham's track record. Panel A provides the complete record of transfers, including transfer fees, as well as free transfer status and loan status when that is the case. Panel B provides the annual statistics across all competitions (league + cup). Note: the estimated market value (MV) of each player is derived from a proprietary formula and hence is not used in our study.

\section{Panel A: Transfers}

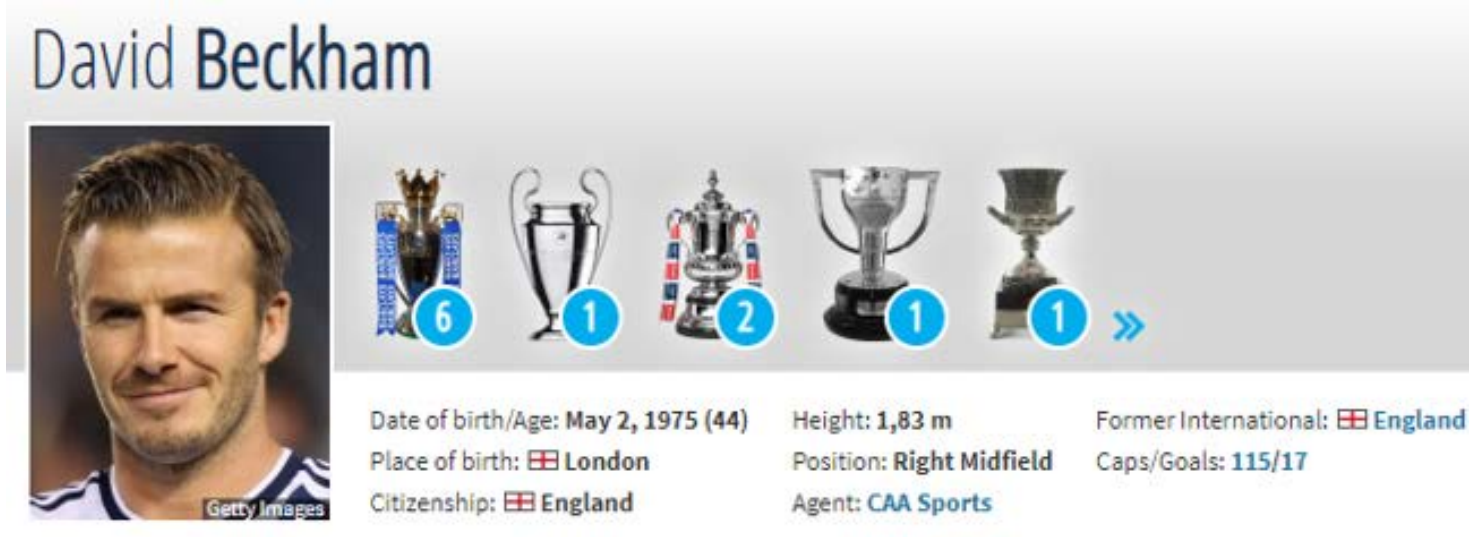

\section{PROFILE STATS - MARKET VALUE tRANSFERS RUMOURS NATIONAL TEAM NEWS ACHIEVEME}

\section{TRANSFER HISTORY}

\begin{tabular}{|c|c|c|c|c|c|c|c|c|c|}
\hline Season & Date & Left & & & Joined & & MV & Fee & \\
\hline $13 / 14$ & Jul 1,2013 & (2) & $\mathbf{n}$ & Paris SG & 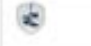 & Retired & - & & $>$ \\
\hline $12 / 13$ & $\operatorname{Jan} 31,2013$ & 웅 & $\Xi$ & LA Galaxy & (2) & Paris SG & $€ 1.00 \mathrm{~m}$ & Free transfer & $>$ \\
\hline $09 / 10$ & Jun 30,2010 & (4) & $\mathbf{n}$ & AC Milan & 曾 & LA Galaxy & $69.00 \mathrm{~m}$ & End of loan & $>$ \\
\hline $09 / 10$ & $\operatorname{Jan} 2,2010$ & 상 & $\Xi$ & LA Galaxy & $\theta \quad 1$ & AC Milan & $\mathrm{eg.00m}$ & Loan & $>$ \\
\hline $08 / 09$ & Jun 30,2009 & $\theta$ & $\mathbf{n}$ & AC Milan & ㅂ. & LA Galaxy & e9.00m & End of loan & $>$ \\
\hline $08 / 09$ & $\operatorname{Jan} 7,2009$ & 붕 & $\varpi$ & LA Galaxy & $\theta$ & AC Milan & $9.00 \mathrm{~m}$ & Loan & $>$ \\
\hline $07 / 08$ & Jul 1, 2007 & (5) & $\square$ & Real Madrid & 面 & LA Galaxy & $€ 19.80 \mathrm{~m}$ & Free transfer & $>$ \\
\hline 03/04 & Jul 1, 2003 & (2) & 田 & Man Utd & (6) & Real Madrid & - & $637.50 \mathrm{~m}$ & $>$ \\
\hline $94 / 95$ & Mar 31, 1995 & E) & 田 & Preston NE & (c) $\mathrm{日}$ & Man Utd & - & End of loan & $>$ \\
\hline $94 / 95$ & $\operatorname{Jan} 1,1995$ & (c) & 田 & Man Utd & E & Preston NE & - & Loan & $>$ \\
\hline $93 / 94$ & Jul 1, 1993 & (2) & 田 & Man Utd U18 & (2) $\mathrm{日}$ & Man Utd & - & - & $>$ \\
\hline $92 / 93$ & Jul 1, 1992 & (2) & 田 & Man Utd Youth & (2) & Man Utd U18 & - & - & $>$ \\
\hline $91 / 92$ & Jul 1, 1991 & 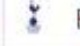 & 田 & Tottenham Yth. & (6) & Man Utd Youth & . & $?$ & $>$ \\
\hline \multicolumn{8}{|c|}{ Total transfer fees: } & $€ 37.50 \mathrm{~m}$ & \\
\hline
\end{tabular}


Panel B: Stats

\begin{tabular}{|c|c|c|c|c|c|c|c|c|}
\hline$\underline{\text { Season }} \pm$ & Competition $\uparrow$ & Club $\uparrow$ & 焉 $\uparrow$ & PPG $\uparrow$ & $\therefore \ddagger$ & $\therefore \ddagger$ & $1 / \mathbf{\Delta} \uparrow$ & (ㄴ) $\uparrow$ \\
\hline $12 / 13$ & Ligue 1 & (2) & 10 & 2,50 & - & 2 & $-/-/ 1$ & $312^{\prime}$ \\
\hline $12 / 13$ & Coupe de France & (a) & 2 & 1,50 & - & - & $1 /-/-$ & $153^{\prime}$ \\
\hline $12 / 13$ & Champions League & (4) & 2 & 1,00 & - & - & $2 /-/-$ & $77^{\prime}$ \\
\hline $12 / 13$ & CONCACAF Champions League & ㅂ. & 1 & 3,00 & 1 & 1 & $1 /-/-$ & $80^{\prime}$ \\
\hline 2012 & MLS Cup Playoffs & 음 & 6 & 2,00 & - & - & $1 /-/-$ & $507^{\prime}$ \\
\hline 2012 & MLS & 曾 & 24 & 1,54 & 7 & 6 & $7 /-/-$ & $1.985^{\prime}$ \\
\hline $11 / 12$ & I CONCACAF Champions League & 요 & 6 & 1,67 & - & 2 & $2 /-/-$ & $526^{\prime}$ \\
\hline 2011 & MLS Cup Playoffs & 요 & 4 & 3,00 & - & 4 & $1 /-/-$ & $348^{\prime}$ \\
\hline 2011 & MLS & ㅂ. & 26 & 1,92 & 2 & 13 & $10 /-/-$ & $2.229^{\prime}$ \\
\hline 2010 & MLS Cup Playoffs & 숭 & 3 & 2,00 & - & 2 & $2 /-/-$ & $270^{\prime}$ \\
\hline 2010 & MLS & 음 & 7 & 2,14 & 2 & 1 & $2 /-/-$ & $466^{\prime}$ \\
\hline $09 / 10$ & (6) Serie A & $\theta$ & 11 & 2,18 & - & 2 & $2 /-/-$ & $666^{\prime}$ \\
\hline $09 / 10$ & 9. Champions League & $\theta$ & 2 & 0,00 & - & - & $-1-1-$ & $98^{\prime}$ \\
\hline 2009 & MLS Cup Playoffs & 畕 & 4 & 1,75 & - & - & $-/-1-$ & $378^{\prime}$ \\
\hline 2009 & MLS & 음 & 11 & 1,91 & 2 & 2 & $2 /-/ 1$ & $889^{\prime}$ \\
\hline $08 / 09$ & (3) Serie A & $\theta$ & 18 & 1,94 & 2 & 5 & $4 /-/-$ & $1.440^{\prime}$ \\
\hline $08 / 09$ & 墨 UEFA Cup & $\theta$ & 2 & 1,00 & - & - & $-1-1-$ & $91^{\prime}$ \\
\hline 2008 & MLS & ㅂ. & 25 & 1,16 & 5 & 8 & $6 /-/-$ & $2.248^{\prime}$ \\
\hline $07 / 08$ & ㄴ. North American SuperLiga & ㅂ. & 2 & 1,50 & 1 & 1 & $1 /-/-$ & $96^{\prime}$ \\
\hline 2007 & MLS & ㅂ. & 5 & 0,20 & - & 2 & $-1-1-$ & $252^{\prime}$ \\
\hline $06 / 07$ & (2) LaLiga & (3) & 23 & 1,91 & 3 & 6 & $14 /-/ 1$ & $1.426^{\prime}$ \\
\hline
\end{tabular}




\section{Figure 2: Relegation, revenues, and wages}

This figure shows the evolution of revenues (Panel A) and wages (Panel B) in event time around the relegation year $(t=0)$ across treatment and control clubs. Specifically, we run a regression in event time around each relegation year whereby the dependent variable is revenues (respectively wages) and the figure plots the yearly coefficients on the treated indicator reflecting the difference in revenues between treated and control every year relative to the baseline at time zero. The $95 \%$ confidence interval is also plotted for each of these coefficients. The specification includes club times relegation year (cohort) fixed effects as well as event year times relegation year (cohort) fixed effects.

Panel A: Revenues

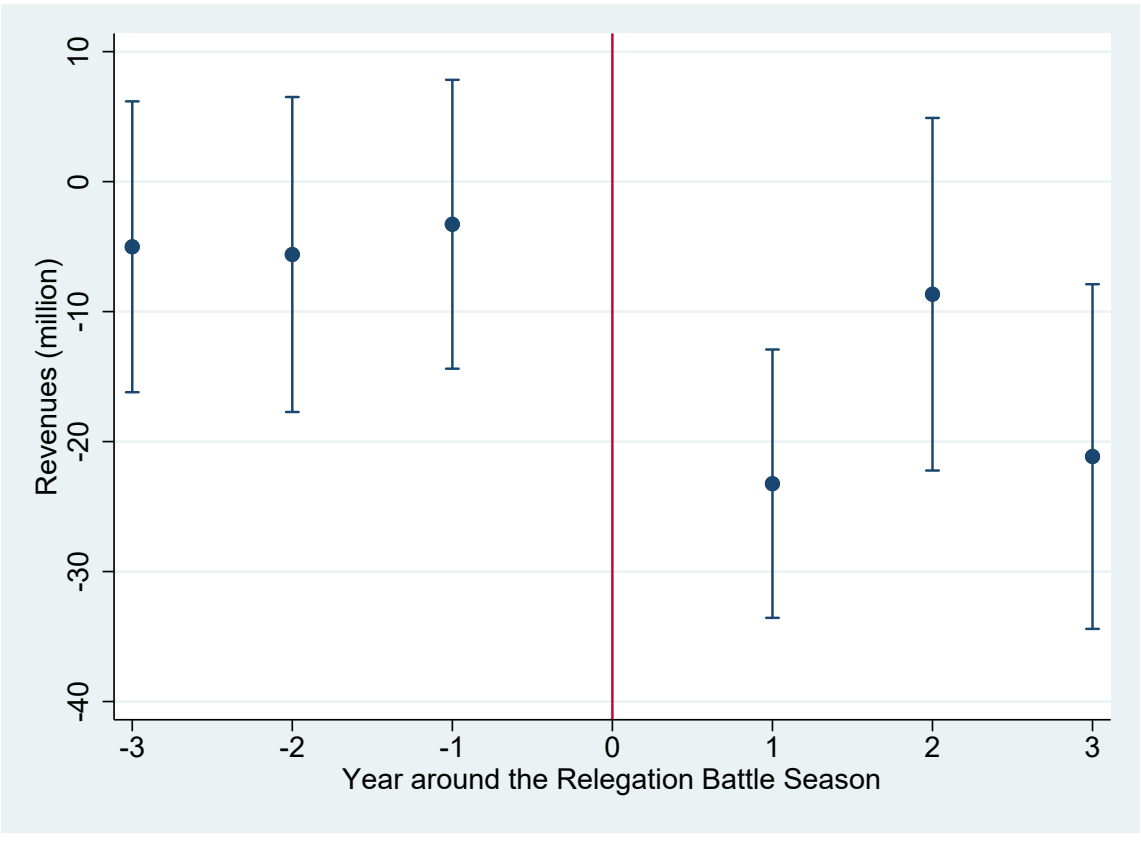

Panel B: Wages

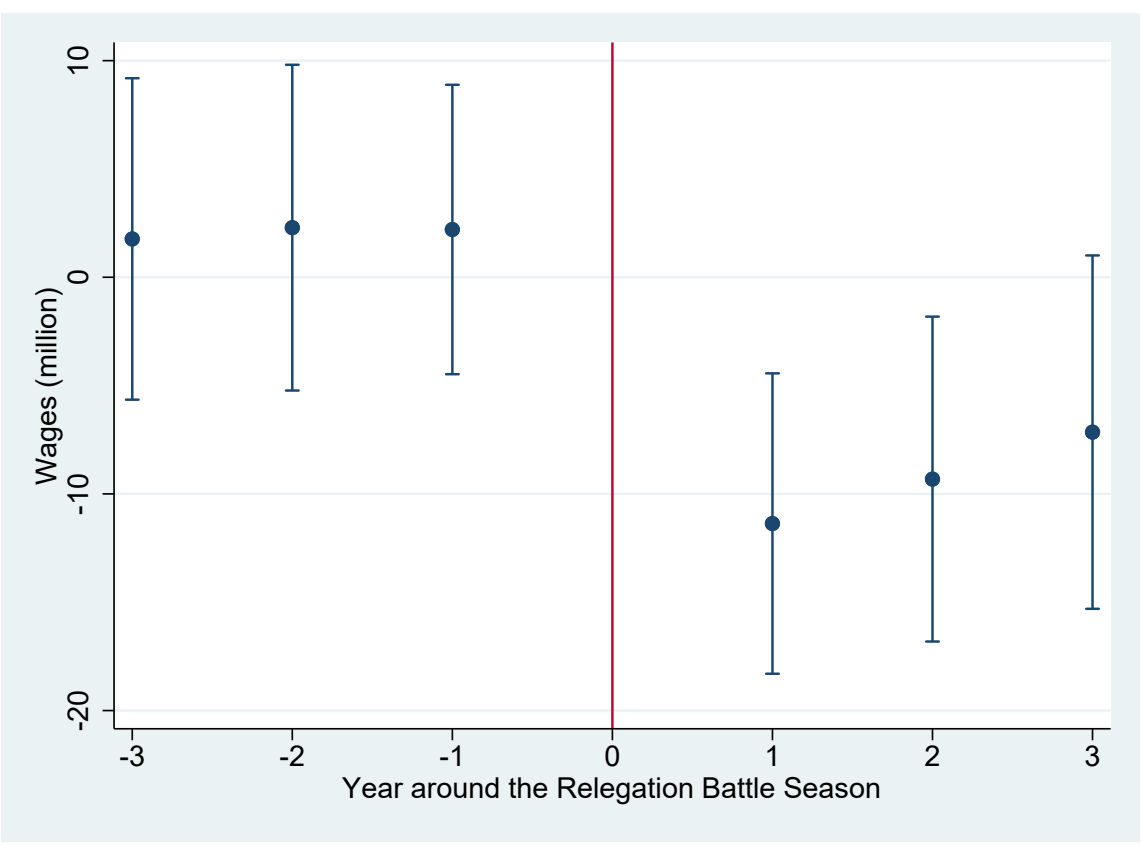




\section{Figure 3: Timing of human capital redeployment}

This figure shows the proportion of players who leave their clubs following a relegation, across both treated (relegated) and control (non-relegated) clubs. The duration is in months. The first two bars represent the proportion of players that leave within the post-relegation summer transfer window (less than four months following relegation). The center bars highlight the proportion of players that leave between 4 months and two years since relegation. And the right bars show the proportion of players that leave two years or more after the relegation.

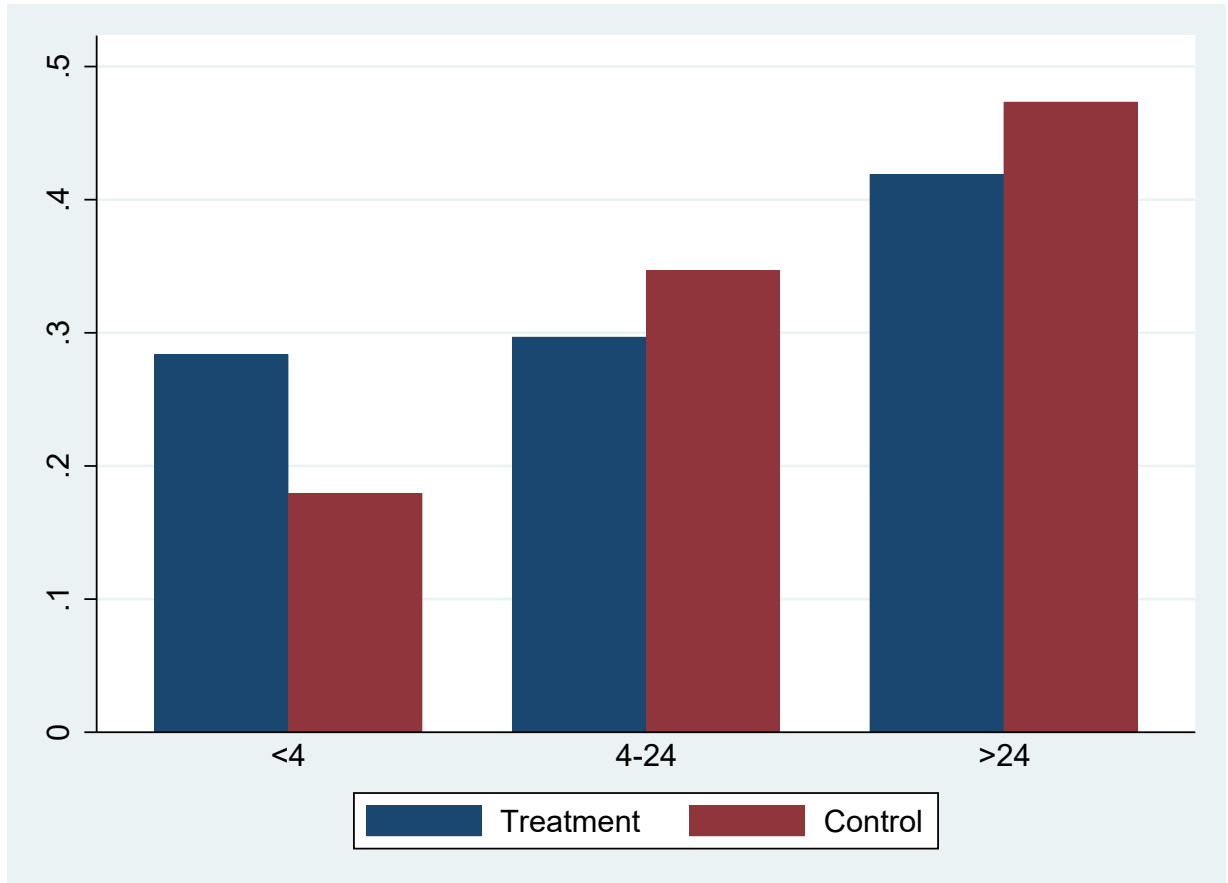




\section{Figure 4: Productivity of human capital transferred}

This figure plots the distribution of productivity for players that leave treatment and control firms within the post-relegation summer transfer window (Panel A), four to 24 months (Panel B) and more than two years (Panel C) post relegation. Human capital productivity is proxied here by the number of minutes played in the Premier League during the relegation season. The reasoning behind this proxy is that more productive players play more often and/or for a longer period of time during each league game.

Panel A: $<4$

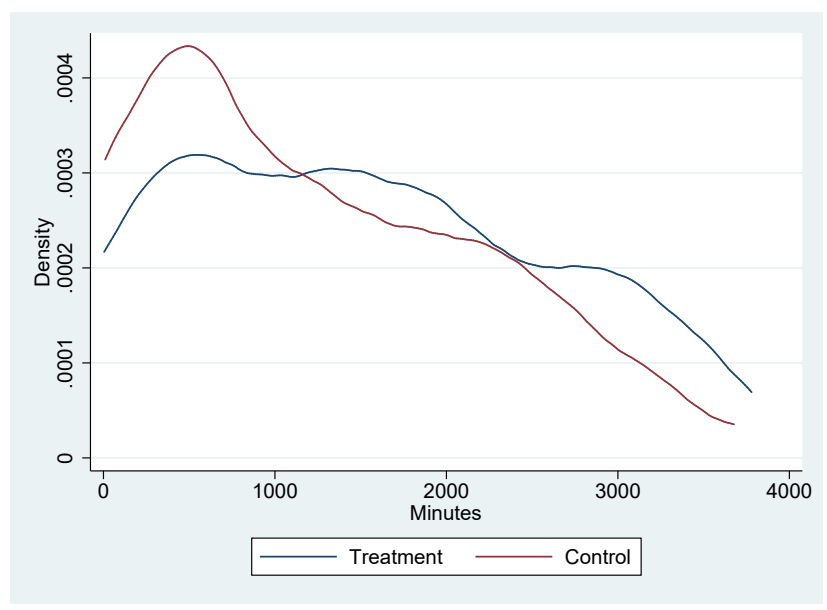

Panel B: 4-24

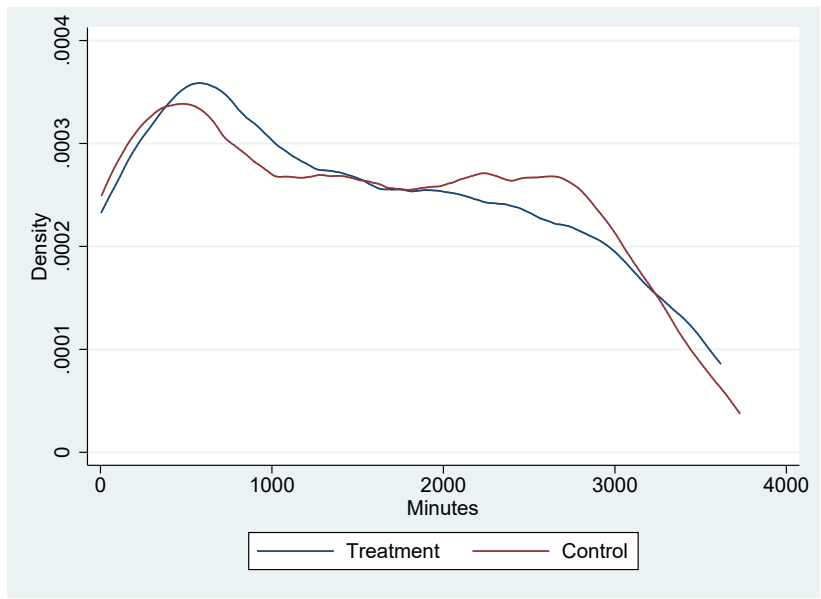

Panel C: $>24$

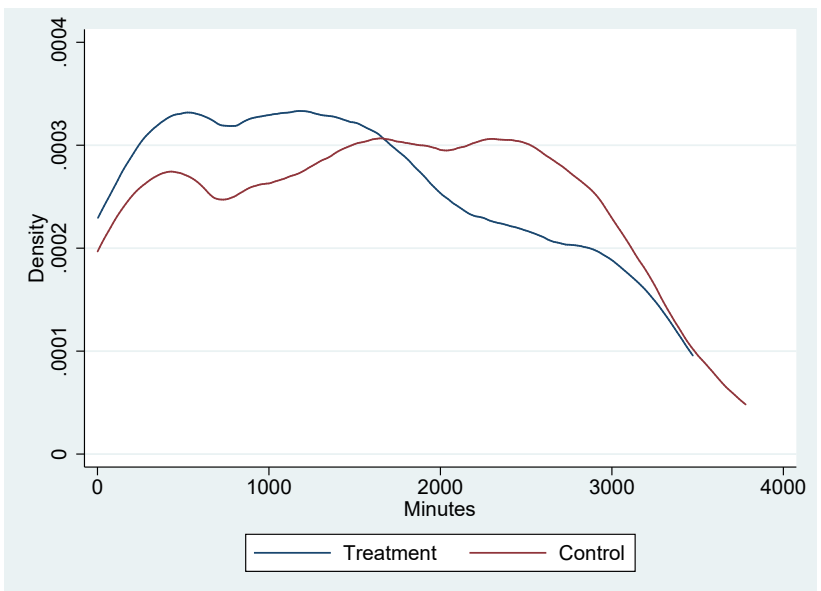




\section{Figure 5: Human capital reallocation}

This figure plots the proportion of players that gets reallocated to clubs in the English Premier League (EPL). For treatment (relegated) firms, it represents the proportion of players that get reallocated to more productive uses. The first two bars (left) represent the proportion that come from those who leave the club within the post-relegation summer transfer window, the second two bars (middle) represent the proportion of those who move to the Premier League within four to 24 months and the last two bars (right) represent the proportion of those who move to the Premier League 24 months after relegation.

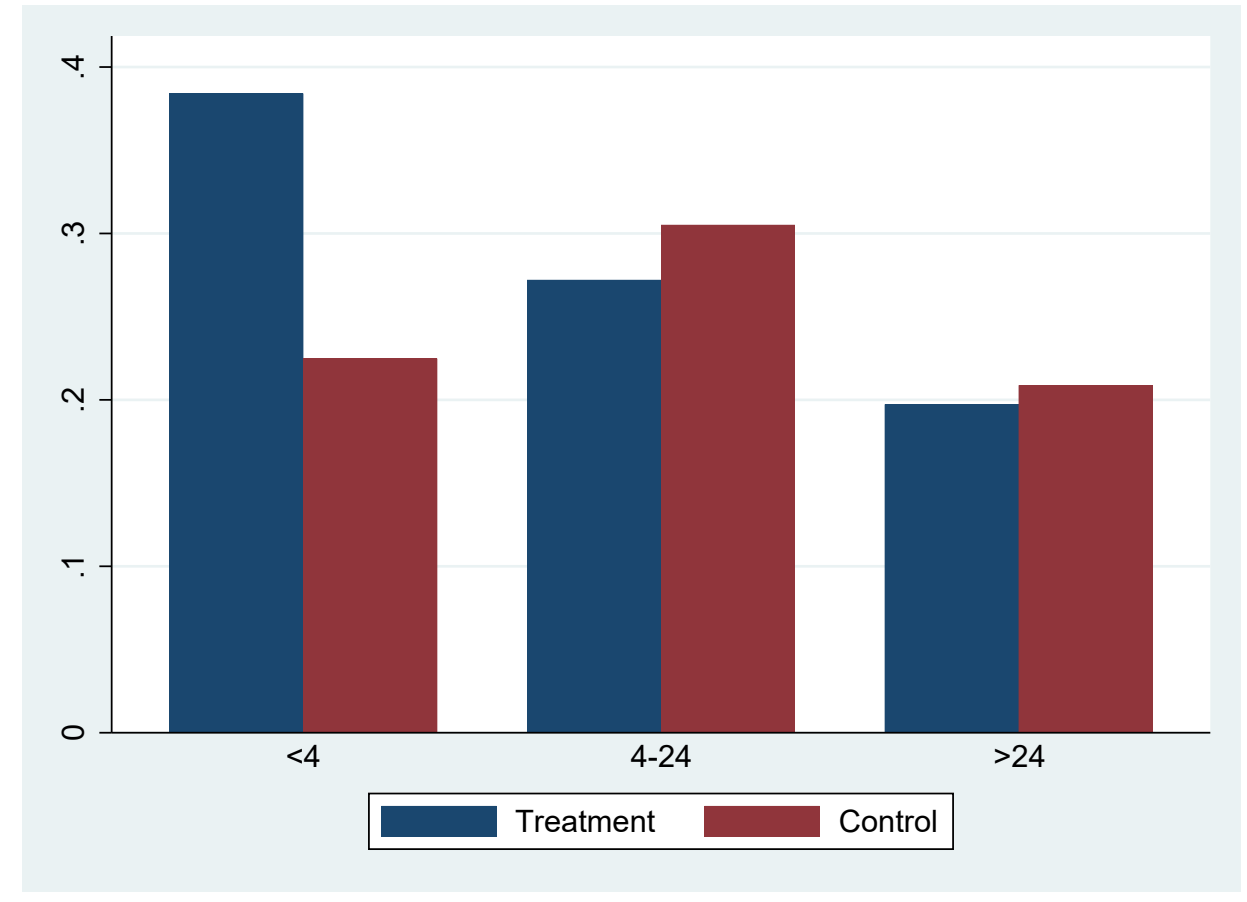


Table 1: Treatment \& control groups

This table highlights the empirical design used to devise a sample of treatment and control groups. whereby treatment firms suffer from a sudden and significant productivity shock relative to their control peers. Specifically, the productivity shock stems from being relegated from the English Premier League (top professional soccer league in England), while control firms maintain their English Premier League (EPL) status. Our design is such that we only consider the seasons whereby the assignment is determined at the very end of the season after the last season game. Panel A highlights the design for the 2010-2011 season. In the left column, we select in grey the clubs that can still be either relegated (within three points of a club in the bottom three positions) or maintain EPL status (within three points of a club above the bottom three clubs). The assignment to treatment and control only occurs after the last game of the season whereby those that could maintain status before the last game but ended up in the bottom three positions are assigned to the treatment group (in red in the right column), while those that could get relegated but managed to maintain their EPL status are assigned to the control group (in green in the right column). This table highlights the quasi-random nature of the assignment as the final ranking depends on the results from all the clubs shaded in grey in the left column as well as all their opponents and how they fared against each other on the last day of the league. Panel B shows the full sample of treatment and control firms stemming from this empirical design for every season since the creation of the English Premier League in 1992 (first season ending in 1993). Note: In the season ending in 1995, four clubs were relegated in order to adjust the league to 20 teams going forward (from 22 teams before). Among the four relegated clubs that season, only Crystal Palace was still able to maintain EPL status going into the last game of the season.

\section{Panel A}

\begin{tabular}{|c|c|c|c|c|c|}
\hline \multicolumn{3}{|c|}{ Before the last game } & \multicolumn{3}{|c|}{ After the last game } \\
\hline Pos & Club & Pts & Pos & Club & Pts \\
\hline 13 & Aston Villa & 45 & 13 & Stoke City & 46 \\
\hline 14 & Sunderland & 44 & 14 & Bolton Wanderers & 46 \\
\hline 15 & Blackburn Rovers & 40 & 15 & Blackburn Rovers & 43 \\
\hline 16 & Wolverhampton Wanderers & 40 & 16 & Wigan Athletic & 42 \\
\hline 17 & Birmingham City & 39 & 17 & Wolverhampton Wanderers & 40 \\
\hline 18 & Blackpool & 39 & 18 & Birmingham City & 39 \\
\hline 19 & Wigan Athletic & 39 & 19 & Blackpool & 39 \\
\hline 20 & West Ham United & 33 & 20 & West Ham United & 33 \\
\hline
\end{tabular}




\section{Panel B}

\begin{tabular}{|c|c|c|c|c|c|c|c|c|c|}
\hline Season & Control_6 & Control_5 & Control_4 & Control_3 & Control_2 & Control_1 & Treatment_1 & Treatment_2 & Treatment_3 \\
\hline 1993 & Sheffield United & & Ipswich Town & & & Oldham Athletic & Crystal Palace & & \\
\hline 1994 & & & Manchester City & Everton & Southampton & Ipswich Town & Sheffield United & Oldham Athletic & \\
\hline 1995 & Sheffield Wednesday & & & & & Aston Villa & Crystal Palace & & \\
\hline 1996 & & & Wimbledon & Sheffield Wednesday & Coventry City & Southampton & Manchester City & & \\
\hline 1997 & & & & & Southampton & Coventry City & Sunderland & Middlesbrough & \\
\hline 1998 & & & & & & Everton & Bolton Wanderers & & \\
\hline 1999 & & & & & & Southampton & Charlton Athletic & & \\
\hline 2000 & & & & & & Bradford City & Wimbledon & & \\
\hline \multicolumn{10}{|l|}{2001} \\
\hline 2002 & & & & & & Sunderland & Ipswich Town & & \\
\hline 2003 & & & & Leeds United & & Bolton Wanderers & West Ham United & & \\
\hline \multicolumn{10}{|l|}{2004} \\
\hline 2005 & & & & & & West Bromwich Albion & Crystal Palace & Norwich City & Southampton \\
\hline \multicolumn{10}{|l|}{2006} \\
\hline 2007 & & & & West Ham United & & Wigan Athletic & Sheffield United & & \\
\hline 2008 & & & & & Bolton Wanderers & Fulham & Reading & Birmingham City & \\
\hline 2009 & & & & & Sunderland & Hull City & Newcastle United & Middlesbrough & \\
\hline \multicolumn{10}{|l|}{2010} \\
\hline 2011 & & & & Blackburn Rovers & Wigan Athletic & Wolverhampton Wanderers & Birmingham City & Blackpool & \\
\hline 2012 & & & & & Aston Villa & Queens Park Rangers & Bolton Wanderers & & \\
\hline \multicolumn{10}{|l|}{2013} \\
\hline 2014 & & & & & & West Bromwich Albion & Norwich City & & \\
\hline 2015 & & & & Newcastle United & & & Hull City & & \\
\hline \multicolumn{10}{|l|}{2016} \\
\hline \multicolumn{10}{|l|}{2017} \\
\hline 2018 & & & & & & Southampton & Swansea City & & \\
\hline
\end{tabular}




\section{Table 2: Summary statistics}

This table presents summary statistics on the key dimensions that we observe both at the club level (Panel A) as well as at the player level (Panel B), and the composition of players (Panel C). In Panel A, we show club-level characteristics: the number of players, the numbers of years in the English Premier League (EPL) in the past five, three and one year prior to the relegation season (Pre5/3/1_EPL), revenues (in GBP) in the relegation season and in the season after relegation, wages expenditures (in GBP) in the relegation season and in the season after relegation. In Panel B, we report player-level statistics in the relegation season and in pre-relegation seasons: appearances, minutes, goals, and assists. We also show player-level characteristics: age, tenure at the club (in months), transfer fees (if any) when joining the club (in USD), the amount of time (in months) a player stays with the firm before they leave after the relegation season, a dummy variable indicating whether a player leaves within the post-relegation summer transfer window, a dummy variable indicating whether a player is transferred to a EPL club in the seasons that follow relegation, the number of seasons in the EPL they experience post relegation season, and the total imputed post-relegation wages. In Panel C, we report the composition of players in our sample.

Panel A: Club-level summary statistics

\begin{tabular}{lcccc}
\hline & N & Mean & Median & Std Dev \\
\hline Number of players & 60 & 20.83 & 21 & 2.92 \\
Pre5_EPL & 60 & 3 & 3.5 & 1.97 \\
Pre3_EPL & 60 & 1.97 & 2.5 & 1.18 \\
Pre1_EPL & 60 & 0.77 & 1 & 0.43 \\
Revenues in the relegation season & 53 & 47.96 & 51.66 & 30.63 \\
Revenues in the season after relegation & 53 & 43.14 & 34.21 & 28.35 \\
Wages in the relegation season & 49 & 33.35 & 34.36 & 23.05 \\
Wages in the season after relegation & 49 & 31.14 & 28.18 & 22.28 \\
\hline
\end{tabular}

Panel B: Player-level summary statistics

\begin{tabular}{lcccc}
\hline & $\mathrm{N}$ & Mean & Median & Std Dev \\
\hline Stats in the relegation season & & & & \\
Appearances & 1250 & 20.02 & 21 & 11.48 \\
Minutes & 1250 & 1504.36 & 1422.50 & 1029.80 \\
Goals & 1250 & 1.73 & 1 & 2.81 \\
Assists & 1250 & 0.55 & 0 & 1.26 \\
\hline Stats in pre-relegation seasons & & & & \\
Appearances & 1250 & 125.97 & 95 & 115.19 \\
Minutes & 1250 & 9768.38 & 7194 & 9180.70 \\
Goals & 1250 & 16.69 & 6 & 26.99 \\
Assists & 1250 & 5.38 & 1 & 9.88 \\
\hline Age & 1250 & 27.22 & 27 & 4.41 \\
Tenure & 1250 & 31.10 & 22 & 27.30 \\
Transfer Fees & 764 & 3485666 & 2166944 & 4072207 \\
Stay & 1250 & 24.38 & 18 & 22.63 \\
Summer_Transfer & 1250 & 0.22 & 0 & 0.42 \\
EPL & 1250 & 0.26 & 0 & 0.44 \\
Post_EPL & 1250 & 2.31 & 1 & 2.67 \\
Post_Wage & 1250 & 11.08 & 7.04 & 11.48 \\
\hline
\end{tabular}

Panel C: Composition of players

\begin{tabular}{lcccc}
\hline Position & Defender & Midfielder & Forward & All \\
\hline $\mathrm{N}$ & 492 & 406 & 352 & 1250 \\
Percentage & $39.36 \%$ & $32.48 \%$ & $28.16 \%$ & $100 \%$ \\
\hline
\end{tabular}




\section{Table 3: Validity of empirical design}

This table reports coefficient estimates from regressions that are designed to test the validity of our empirical design. In Panel A, we test whether there are significant club-level differences between treatment and control firms at the onset of the shock. Specifically, we run a regression of the numbers of years in the English Premier League (EPL) in the past five (left column), three (middle column) and one (right column) year prior to the relegation season. We include both a treated dummy, as well as cohort (relegation year) fixed effects. In Panel B, we test whether there are significant player-level differences across treatment and control firms. In each of the columns, we have a player-level characteristic explained by a treatment dummy as well as cohort (relegation year) fixed effects. The first four columns (1)-(4) reports on player-level statistics in the relegation season, namely number of game appearances, minutes played, goals scored and assists made. The next four columns (5)-(8) focus on the player-level statistics from their entire career up to the beginning of the relegation season. The last three columns run the same regressions as before on the following player-level characteristics: age, tenure at the club (in months), and transfer fees (if any) when joining the club (in USD). T-stats are reported in parentheses. ${ }^{*},{ }^{* *},{ }^{* *}$ indicate significance at the $10 \%, 5 \%$, and $1 \%$ levels, respectively.

Panel A: Club-level regressions

\begin{tabular}{lccc}
\hline & Pre5_EPL & Pre3_EPL & Pre1_EPL \\
& $(1)$ & $(2)$ & $(3)$ \\
\hline Treated & -0.635 & -0.353 & -0.156 \\
& $(-1.16)$ & $(-1.08)$ & $(-1.32)$ \\
\hline Cohort FE & $\checkmark$ & $\checkmark$ & $\checkmark$ \\
Observations & 60 & 60 & 60 \\
R-squared & 0.275 & 0.278 & 0.280 \\
\hline
\end{tabular}

Panel B: Player-level regressions

\begin{tabular}{|c|c|c|c|c|c|c|c|c|c|c|c|}
\hline & \multicolumn{4}{|c|}{ Stats in relegation season } & \multicolumn{4}{|c|}{ Stats in pre-relegation seasons } & \multirow[b]{2}{*}{$\begin{array}{c}\text { Age } \\
(9) \\
\end{array}$} & \multirow[b]{2}{*}{$\begin{array}{c}\text { Tenure } \\
(10)\end{array}$} & \multirow[b]{2}{*}{$\begin{array}{c}\text { Transfer Fees } \\
(11)\end{array}$} \\
\hline & $\begin{array}{c}\text { Appearances } \\
\text { (1) }\end{array}$ & $\begin{array}{c}\text { Minutes } \\
(2)\end{array}$ & $\begin{array}{c}\text { Goals } \\
(3)\end{array}$ & $\begin{array}{c}\text { Assists } \\
(4)\end{array}$ & $\begin{array}{c}\text { Appearances } \\
(5)\end{array}$ & $\begin{array}{c}\text { Minutes } \\
(6)\end{array}$ & $\begin{array}{c}\text { Goals } \\
(7)\end{array}$ & $\begin{array}{c}\text { Assists } \\
(8)\end{array}$ & & & \\
\hline Treated & $\begin{array}{l}-0.114 \\
(-0.29)\end{array}$ & $\begin{array}{l}4.850 \\
(0.15)\end{array}$ & $\begin{array}{c}-0.0144 \\
(-0.18)\end{array}$ & $\begin{array}{l}0.0517 \\
(1.28)\end{array}$ & $\begin{array}{l}-9.158 \\
(-1.41)\end{array}$ & $\begin{array}{l}-704.1 \\
(-1.37)\end{array}$ & $\begin{array}{l}-1.688 \\
(-1.36)\end{array}$ & $\begin{array}{l}0.211 \\
(0.48)\end{array}$ & $\begin{array}{l}-0.188 \\
(-0.64)\end{array}$ & $\begin{array}{l}0.368 \\
(0.23)\end{array}$ & $\begin{array}{c}-175405.1 \\
(-0.35)\end{array}$ \\
\hline Cohort FE & $\checkmark$ & $\checkmark$ & $\checkmark$ & $\checkmark$ & $\checkmark$ & $\checkmark$ & $\checkmark$ & $\checkmark$ & $\checkmark$ & $\checkmark$ & $\checkmark$ \\
\hline Observations & 1250 & 1250 & 1250 & 1250 & 1250 & 1250 & 1250 & 1250 & 1250 & 1250 & 764 \\
\hline R-squared & 0.01 & 0.02 & 0.01 & 0.21 & 0.26 & 0.22 & 0.09 & 0.30 & 0.01 & 0.03 & 0.18 \\
\hline
\end{tabular}




\section{Table 4: Timing of human capital redeployment}

This table presents regression estimates related to the timing of human capital redeployment. In the first column, we model the amount of time (in months) a player stays with the firm before they leave after the relegation season. In the second column, we estimate the likelihood of a post-relegation summer transfer, defined as leaving within three months of being relegated (and prior to the start of the next season), using a linear probability model. In the third column, we estimate the likelihood of a post-relegation summer transfer using a logistic model and report the odds ratio. For each specification, we include a treatment dummy as well as cohort (relegation year) fixed effects. Standard errors are clustered at the club-relegation year level. T-stats (z-stats) are reported in parentheses. *,**,*** indicate significance at the 10\%, $5 \%$, and $1 \%$ levels, respectively.

\begin{tabular}{lccc}
\hline & & LPM & Logit \\
& Stay & Summer_Transfer & Summer_Transfer \\
& $(1)$ & $(2)$ & $(3)$ \\
\hline Treated & $-4.271^{* * *}$ & $0.0961^{* * *}$ & $1.745^{* * *}$ \\
& $(-3.90)$ & $(3.58)$ & $(3.73)$ \\
\hline Cohort FE & $\checkmark$ & $\checkmark$ & $\checkmark$ \\
Observations & 1250 & 1250 & 1250 \\
R-squared & 0.05 & 0.03 & 0.03 \\
\hline
\end{tabular}




\section{Table 5: Productivity of human capital transferred}

This table presents OLS regression estimates related to the productivity of departing human capital for the treatment and control firms. Productivity is measured as (1) the number of appearances in the previous season (column 1), (2) the number of minutes played in the previous season (column 2), (3) the number of goals scored in the previous season (column 3) and (4) the number of assists made in the previous season (column 4). For each specification, we include a treatment dummy (Treated), a dummy that takes the value of 1 for all transactions within three months of relegation (Summer_Transfer), and the interaction term of the two (Treated $\times$ Summer_Transfer), as well as cohort (relegation year) fixed effects. Standard errors are clustered at the club-relegation year level. T-stats are reported in parentheses. ${ }^{*},{ }^{* *}, * * *$ indicate significance at the $10 \%, 5 \%$, and $1 \%$ levels, respectively.

\begin{tabular}{lcccc}
\hline & Appearances & Minutes & Goals & Assists \\
& $(1)$ & $(2)$ & $(3)$ & $(4)$ \\
\hline Treated & -1.059 & -84.17 & $-0.220^{*}$ & -0.0235 \\
& $(-1.62)$ & $(-1.58)$ & $(-1.83)$ & $(-0.37)$ \\
Summer_Transfer & $-3.928^{* * *}$ & $-349.0^{* * *}$ & -0.198 & $-0.228^{*}$ \\
& $(-3.48)$ & $(-3.55)$ & $(-0.75)$ & $(-1.71)$ \\
Treated $\times$ Summer_Transfer & $4.712^{* * *}$ & $436.7^{* * *}$ & $0.801^{* *}$ & $0.346^{*}$ \\
& $(2.68)$ & $(2.89)$ & $(2.04)$ & $(1.93)$ \\
\hline Cohort FE & $\checkmark$ & $\checkmark$ & $\checkmark$ & $\checkmark$ \\
Observations & 1250 & 1250 & 1250 & 1250 \\
R-squared & 0.02 & 0.03 & 0.02 & 0.21 \\
\hline
\end{tabular}




\section{Table 6: Productivity of replacement human capital}

This table presents OLS regression estimates related to the productivity of replacement human capital by the treatment and control firms. Productivity is measured as (1) the number of appearances in the previous season (column 1), (2) the number of minutes played in the previous season (column 2), (3) the number of goals scored in the previous season (column 3) and (4) the number of assists made in the previous season (column 4). For each specification, the sample consists of all departures and arrivals of players for treated and control firms within the post-relegation summer transfer window. We include a treatment dummy (Treated), a replacement dummy (Replacement), and the interaction term of the two (Treated $\times$ Replacement), as well as cohort (relegation year) fixed effects. Standard errors are clustered at the club-relegation year level. Tstats are reported in parentheses. ${ }^{*},{ }^{* *},{ }^{* *}$ indicate significance at the $10 \%, 5 \%$, and $1 \%$ levels, respectively.

\begin{tabular}{lcccc}
\hline & Appearances & Minutes & Goals & Assists \\
& $(1)$ & $(2)$ & $(3)$ & $(4)$ \\
\hline Treated & $4.815^{* * *}$ & $416.1^{* * *}$ & $0.673^{* * *}$ & $0.318^{* * *}$ \\
& $(4.11)$ & $(4.36)$ & $(2.94)$ & $(2.66)$ \\
Replacement & $-6.258^{* * *}$ & $-430.8^{* * *}$ & $-0.604^{* * *}$ & -0.0681 \\
& $(-4.76)$ & $(-4.05)$ & $(-2.73)$ & $(-0.58)$ \\
Treated $\times$ Replacement & $-6.303^{* * *}$ & $-562.9^{* * *}$ & $-0.926^{* * *}$ & $-0.405^{* *}$ \\
& $(-3.60)$ & $(-3.97)$ & $(-3.32)$ & $(-2.22)$ \\
\hline Cohort FE & $\checkmark$ & $\checkmark$ & $\checkmark$ & $\checkmark$ \\
Observations & 711 & 711 & 711 & 711 \\
R-squared & 0.19 & 0.18 & 0.09 & 0.10 \\
\hline
\end{tabular}




\section{Table 7: Human capital reallocation}

This table presents regression results related to the human capital reallocation following the relegation season. The model explains the likelihood of having a player transferred to an English Premier League (EPL) club in the seasons that follow relegation. The model includes a treatment (relegated) dummy, a post-relegation summer transfer dummy (Summer_Transfer) and the interaction term (Treated $\times$ Summer_Transfer), as well as cohort (relegation year) fixed effects. In Column 1, we use a linear probability model (LPM). In Column 2, we use a logistic model (Logit) and report the odds ratio. Standard errors are clustered at the club-relegation year level. T-stats are reported in parentheses. ${ }^{*}, * *, * * *$ indicate significance at the $10 \%, 5 \%$, and $1 \%$ levels, respectively.

\begin{tabular}{lcc}
\hline & LPM & Logit \\
& EPL & EPL \\
& $(1)$ & $(2)$ \\
\hline Treated & -0.0211 & 0.885 \\
& $(-0.64)$ & $(-0.67)$ \\
Summer_Transfer & -0.0240 & 0.871 \\
& $(-0.54)$ & $(-0.54)$ \\
Treated $\times$ Summer_Transfer & $0.176^{* * *}$ & $2.439^{* * *}$ \\
& $(2.75)$ & $(2.68)$ \\
\hline Cohort FE & $\checkmark$ & $\checkmark$ \\
Observations & 1250 & 1250 \\
R-squared & 0.04 & 0.04 \\
\hline
\end{tabular}




\section{Table 8: Long-term impact on human capital productivity}

This table presents regression estimates of the long-term impact of relegation on human capital productivity. In Panel A, we take all treatment and control players and trace over time the number of seasons in the English Premier League (EPL) they experience post relegation season in column 1 and the total imputed post-relegation wages in column 2. The models include a treatment (relegated) dummy, a post-relegation summer transfer dummy (Summer_Transfer) and the interaction term (Treated $\times$ Summer_Transfer), as well as cohort (relegation year) fixed effects. In Panel B, we compare along the same two proxies for long-term human capital productivity across treatment and control clubs, focusing only on the subset of players who are in the EPL the season following relegation. That is, we focus only on the subset of players who (1) were among the treated clubs but left for an EPL club in the post-relegation summer transfer window or (2) were in a control club and stayed for at least another season in that club or left for another EPL club during the summer transfer window. The models include a treatment (relegated) dummy and cohort (relegation year) fixed effects. All regressions include control variables that measure human capital productivity in the relegation season. Standard errors are clustered at the club-relegation year level. Tstats are reported in parentheses. ${ }^{*},{ }^{* *},{ }^{* *}$ indicate significance at the $10 \%, 5 \%$, and $1 \%$ levels, respectively.

\section{Panel A: All players}

\begin{tabular}{lcc}
\hline & $\begin{array}{c}\text { Post_EPL } \\
(1)\end{array}$ & $\begin{array}{c}\text { Post_Wage } \\
(2)\end{array}$ \\
\hline Treated & $-1.375^{* * *}$ & $-3.030^{* * *}$ \\
& $(-5.62)$ & $(-3.07)$ \\
Summer_Transfer & $-1.959^{* * *}$ & $-6.926^{* * *}$ \\
& $(-7.42)$ & $(-5.85)$ \\
Treated $\times$ Summer_Transfer & $1.874^{* * *}$ & $4.800^{* * *}$ \\
& $(5.13)$ & $(3.08)$ \\
\hline Cohort FE & $\checkmark$ & $\checkmark$ \\
Controls & $\checkmark$ & $\checkmark$ \\
Observations & 1250 & 1250 \\
R-squared & 0.23 & 0.20 \\
\hline
\end{tabular}

Panel B: Players who stay in EPL after the relegation season

\begin{tabular}{lcc}
\hline & $\begin{array}{c}\text { Post_EPL } \\
(1)\end{array}$ & $\begin{array}{c}\text { Post_Wage } \\
(2)\end{array}$ \\
\hline Treated & 0.593 & $3.438^{*}$ \\
& $(1.32)$ & $(1.82)$ \\
\hline Cohort FE & $\checkmark$ & $\checkmark$ \\
Controls & $\checkmark$ & $\checkmark$ \\
Observations & 676 & 676 \\
R-squared & 0.18 & 0.19 \\
\hline
\end{tabular}




\section{Table 9: Placebo tests}

This table presents regression results on the timing of human capital redeployment (Panel A), the productivity of human capital transferred (Panel B), human capital reallocation (Panel C), and the long-term impact on human capital productivity (Panel D) in response to a placebo event. The placebo event is defined in the following way: instead of using the appropriate relegation cutoff for any given season, we use a placebo cutoff three ranks above the actual cutoff. Every season, we define the placebo treated firms as the three firms below the placebo cutoff and the placebo control firms as the three firms above the placebo cutoff. Note that none of the placebo control or treated firms actually get relegated at the end of the season. The detailed description of the estimation in Panel A/B/C/D can be found in Tables 4/5/7/8 respectively. Standard errors are clustered at the club-relegation year level. Tstats are reported in parentheses. ${ }^{*}, * *, * * *$ indicate significance at the $10 \%, 5 \%$, and $1 \%$ levels, respectively.

Panel A: Timing of human capital redeployment

\begin{tabular}{lcc}
\hline & Stay & Summer_Transfer \\
& $(1)$ & $(2)$ \\
\hline Treated_Placebo & -0.552 & -0.00780 \\
& $(-0.55)$ & $(-0.49)$ \\
\hline Cohort FE & $\checkmark$ & $\checkmark$ \\
Observations & 2263 & 2263 \\
R-squared & 0.02 & 0.02 \\
\hline
\end{tabular}

Panel B: Productivity of human capital transferred

\begin{tabular}{lcccc}
\hline & Appearances & Minutes & Goals & Assists \\
& $(1)$ & $(2)$ & $(3)$ & $(4)$ \\
\hline Treated_Placebo & 0.124 & 14.14 & -0.0914 & $-0.108^{* * *}$ \\
& $(0.26)$ & $(0.36)$ & $(-1.13)$ & $(-2.92)$ \\
Summer_Transfer & $-3.500^{* * *}$ & $-313.3^{* * *}$ & -0.164 & $-0.184^{* *}$ \\
& $(-3.56)$ & $(-3.63)$ & $(-0.76)$ & $(-2.13)$ \\
Treated_Placebo $\times$ Summer_Transfer & 0.485 & 15.73 & 0.0845 & 0.0510 \\
& $(0.34)$ & $(0.13)$ & $(0.28)$ & $(0.39)$ \\
\hline Cohort FE & $\checkmark$ & $\checkmark$ & $\checkmark$ & $\checkmark$ \\
Observations & 2263 & 2263 & 2263 & 2263 \\
R-squared & 0.02 & 0.03 & 0.01 & 0.21 \\
\hline
\end{tabular}


Panel C: Human capital reallocation

\begin{tabular}{lc}
\hline & EPL \\
& $(1)$ \\
\hline Treated_Placebo & -0.00155 \\
& $(-0.06)$ \\
Summer_Transfer & 0.0385 \\
& $(1.08)$ \\
Treated_Placebo $\times$ Summer_Transfer & -0.0409 \\
& $(-0.80)$ \\
\hline Cohort FE & $\checkmark$ \\
Observations & 2263 \\
R-squared & 0.02 \\
\hline
\end{tabular}

Panel D: Long-term impact on human capital productivity

\begin{tabular}{lcccc}
\hline & \multicolumn{2}{c}{ All players } & \multicolumn{2}{c}{ Players staying in EPL } \\
& Post_EPL & Post_Wage & Post_EPL & Post_Wage \\
& $(1)$ & $(2)$ & $(3)$ & $(4)$ \\
\hline Treated_Placebo & -0.258 & -1.016 & -0.124 & 0.847 \\
& $(-1.44)$ & $(-1.27)$ & $(-0.42)$ & $(0.57)$ \\
Summer_Transfer & $-1.530^{* * *}$ & $-5.418^{* * *}$ & & \\
& $(-7.29)$ & $(-5.47)$ & & \\
Treated_Placebo $\times$ Summer_Transfer & -0.384 & -1.629 & & \\
& $(-1.28)$ & $(-1.16)$ & & \\
\hline Cohort FE & $\checkmark$ & $\checkmark$ & $\checkmark$ & $\checkmark$ \\
Controls & $\checkmark$ & $\checkmark$ & $\checkmark$ & $\checkmark$ \\
Observations & 2263 & 2263 & 971 & 971 \\
R-squared & 0.21 & 0.19 & 0.15 & 0.15 \\
\hline
\end{tabular}




\section{Internet Appendix}

\section{Figure A.1: Timeline of EPL}

This figure provides the timeline following any given English Premier League (EPL) season and the corresponding transfer windows during which players can move from one club to another. The summer transfer window that starts after the end of the season lasts about three months from May to August. This is the window whereby most players transfer from one club to another. There is a shorter (and much less used) mid-season transfer window in January as well.

\section{Relegation Season}

\section{Summer Transfer}

May

Relegated clubs are determined Summer transfer window opens
Aug

Summer transfer window closes

Next season starts

\section{Next Season}

Jan

Winter transfer window

May

Next season ends 


\section{Figure A.2: Evolution of club rankings around the relegation cutoff}

This figure provides the evolution of club rankings around the relegation cutoff over the last eight games of the 2010-2011 season in the English Premier League (EPL). Specifically, it graphs the dynamic ranking of the clubs that end the league season in the bottom nine positions in the league table; namely the bottom three below the "relegation bar" (cutoff) as well as the six clubs above the cutoff. The bottom three clubs are relegated to play in the lower league (Championship League) the following season, while all other clubs maintain their EPL status the following season. As a visual aid, we plot with continuous lines the evolution of the clubs that are respectively just below (above) the relegation cutoff at the end of the season.

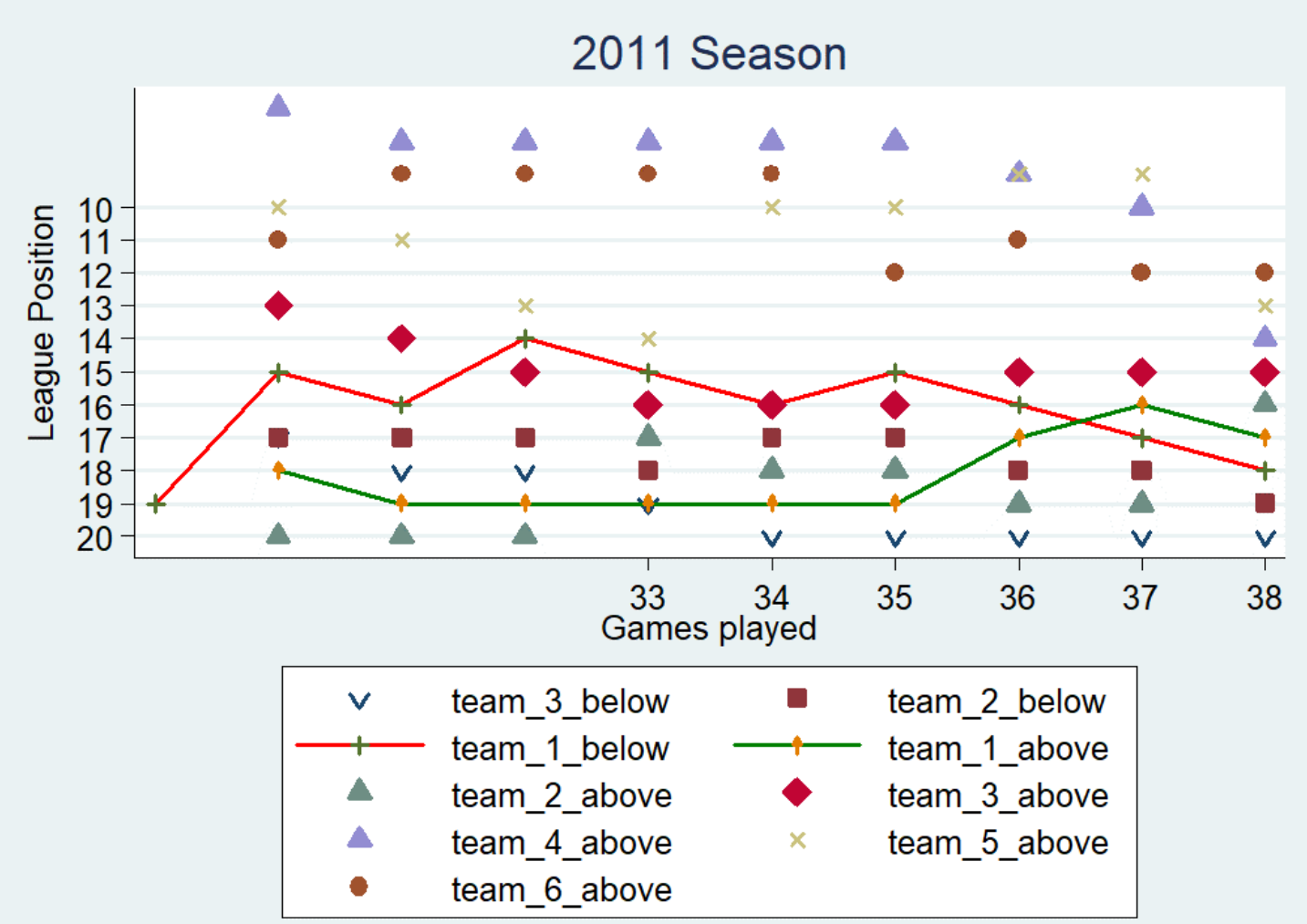

